\title{
Differentiation and homing of IgA-secreting cells
}

\author{
$\mathrm{JR}_{\text {Mora }}{ }^{1}$ and UH von Andrian ${ }^{2}$
}

\begin{abstract}
Most antibody-secreting cells (ASCs) in mucosal tissues produce immunoglobulin A (IgA), the most abundant immunoglobulin in the body and the main class of antibody found in secretions. IgA-ASCs differentiate in the mucosal-associated lymphoid tissues and are usually considered as a homogeneous population of cells. However, IgA-ASCs that travel to the small intestine have unique characteristics in terms of their migratory requirements. These IgA-ASCs require the homing molecules $\alpha 4 \beta 7$ and CCR9 to interact with their ligands, mucosal addressin cell adhesion molecule-1 and CCL25, which are constitutively expressed in the small intestine. Indeed, recent work has shown that IgA-ASCs specific for the small bowel are generated under different conditions as compared with IgA-ASCs in other mucosal compartments. Moreover, the mechanisms inducing lgA class switching may also vary according to the tissue where IgA-ASCs differentiate. Here we describe the mechanisms involved in the differentiation of IgA-ASCs in mucosal compartments, in particular those involved in the generation of gut-homing IgA-ASCs.
\end{abstract}

Immunoglobulin A (IgA) is the most abundant immunoglobulin isotype produced in the body and it is estimated that around $80 \%$ of all IgA-antibody-secreting cells (IgA-ASCs) reside in the gut mucosa. ${ }^{1,2}$ The importance of secretory IgA is evidenced by the fact that mice deficient in the J-chain, which produce only monomeric IgA that cannot be secreted, show markedly decreased protection from intestinal toxins. ${ }^{3}$ Similarly, mice that cannot secrete antibodies because they lack the polymeric Ig receptor (pIgR or secretory component) exhibit a higher susceptibility to primary Salmonella infections, ${ }^{4}$ although they have normal recall responses. ${ }^{5}$ However, other studies using mice deficient in IgA show that they can efficiently mount protective immune responses against respiratory and gastrointestinal mucosal pathogens. ${ }^{6,7}$ Therefore, in spite of its massive production in mucosal tissues, the physiological significance of IgA is still being debated. Nonetheless, it has been proposed that, aside from its role in neutralizing toxins and protecting against pathogenic infections, IgA, owing to its lack of complement-activating capacity and its binding to the inhibitory Fc $\alpha$ RI receptor, may play a role as a noninflammatory mechanism of "immune exclusion" in the gut. ${ }^{8-10}$ In this way, IgA may help to prevent local inflammation and systemic immune responses triggered by innocuous antigens and/or commensal flora.,2,11 In fact, although isolated IgA deficiency in humans translates into only a mild and often asymptomatic primary immunodeficiency, it has been associated with autoimmune pathologies such as celiac disease. ${ }^{12}$
On the other hand, the migration of B cells and ASCs to the gut is critical for conferring protection against intestinal pathogens. ${ }^{7,13-16} \mathrm{~B}$ cells that lack gut-homing capacity confer poor protection against intestinal rotavirus infection, whereas guthoming B cells from IgA knockout mice are as protective as wild-type cells. ${ }^{7}$ The latter example suggests that, at least for some infections, the capacity of ASCs to migrate to the gut may be more important than their capacity to secrete IgA in order to confer protective immune responses.

In this review, we will discuss our current understanding of the mechanisms imprinting tissue-specific migration onto activated $B$ cells as well as their relationship and potential intersection with the complex mechanisms involved in the differentiation of IgA-ASCs in mucosal tissues.

\section{HOMING OF NAIVE B CELLS}

Naive B lymphocytes migrate to secondary lymphoid organs (lymph nodes, Peyer's patches (PPs), spleen), where they are activated by their cognate antigen. ${ }^{17}$ Naive $B$ cells use L-selectin (CD62L) to tether and roll on specialized postcapillary microvessels known as high endothelial venules (HEVs), which are found in peripheral lymph nodes (PLNs), mesenteric lymph nodes (MLNs), and PPs ${ }^{18,19}$ (Figure 1). HEVs in PLNs and MLNs express L-selectin ligands, collectively known as peripheral node addressin. ${ }^{20-22}$ In addition, the chemokines CCL21/SLC and CCL19/ELC are presented in HEVs of LN and PPs and they bind to CCR7 expressed on naive B cells, ${ }^{23-26}$

\footnotetext{
${ }^{1}$ Gastrointestinal Unit, Massachusetts General Hospital, Harvard Medical School, Boston, Massachusetts, USA. ${ }^{2}$ Immune Disease Institute \& Department of Pathology, Harvard Medical School, Boston, Massachusetts, USA. Correspondence: JR Mora (j_rodrigo_mora@harvard.hms.edu) or UH von Andrian (uva@harvard.hms.edu) 


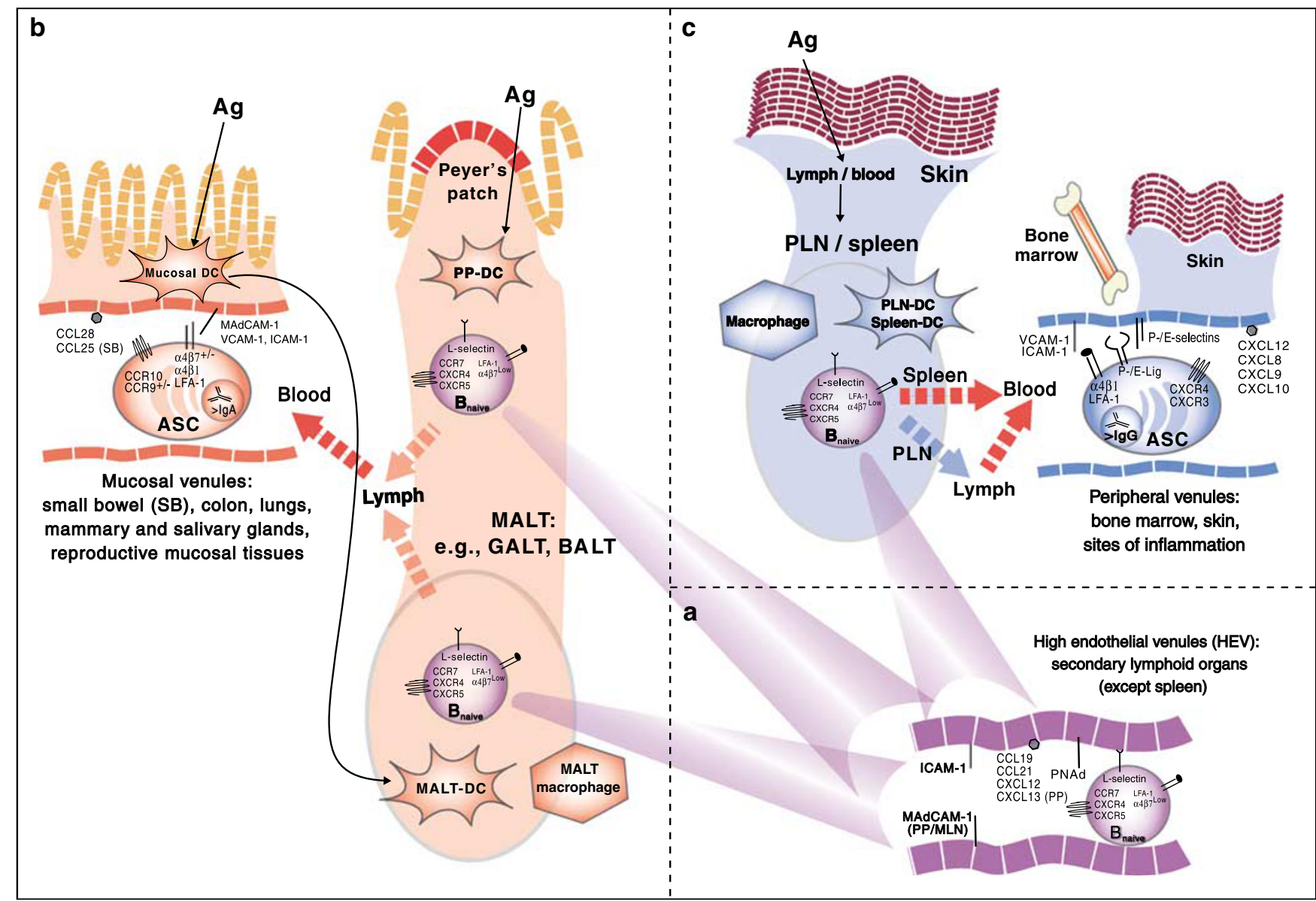

Figure 1 Homing of naive and antigen-experienced B cells. (a) Naive B cells access MLNs, PPs, other MALTs, and PLNs through HEVs. DCs and/or subcapsular macrophages interact with and present antigens (in their native conformation) to naive B cells in vivo. Also, B cells are likely to require DCs to differentiate efficiently into ASCs. (b) DCs in PPs and MLNs present orally administered antigens to B cells, inducing their differentiation into ASC-expressing the gut-homing receptors $\alpha 4 \beta 7$ and CCR9. Furthermore, ASCs migrating to all mucosal compartments express CCR10, and the CCR10 ligand MEC/CCL28 is expressed in all mucosal tissues. In addition, B cells activated in PPs, MLNs, and other MALTs can become IgA-ASCs. (c) If $B$ cells are activated in peripheral nonmucosal lymphoid tissues (such as PLNs or spleen), they do not upregulate gut-homing receptors or switch to IgA. Instead, they home to the bone marrow, skin, and sites of inflammation and switch to other immunoglobulin isotypes, such as IgG. Once B cells are activated in the lymphoid organs, the resulting $B_{\text {Mem }}$ and ASCs leave the lymphoid tissues via lymphatics (except in the spleen where they go directly to the blood), reach the blood, and home to the respective peripheral tissues through postcapillary venules, which express the corresponding tissue-specific ligands (addressins). Ag, antigen; ASC, antibody-secreting cell; $\mathrm{B}_{\mathrm{Mem}}$ memory B cell; BALT, bronchus-associated lymphoid tissue; DC, dentritic cell; GALT, gut-associated lymphoid tissue; HEV, high endothelial venule; MALT, mucosal-associated lymphoid tissue; MLN, mesenteric lymph node; PLN, peripheral lymph node; PP, Peyer's patch.

triggering the activation of integrins LFA-1 and/or $\alpha 4 \beta 7$ and lymphocyte arrest in HEVs. ${ }^{18,19,27}$ Naive B cells can also use CXCR4 for integrin activation; the CXCR4 ligand CXCL12/SDF1a is presented in PLN-HEVs. ${ }^{25}$ In addition, the CXCR5-CXCL13 pathway can also support naive B cell homing. ${ }^{25,28}$

In PPs, HEVs do not express peripheral node addressin in the lumen..$^{21}$ Instead, they express high levels of MAdCAM1 (mucosal addressin cell adhesion molecule-1). ${ }^{29}$ MAdCAM- 1 in PPs can interact with both L-selectin and $\alpha 4 \beta 7 .{ }^{30,31}$ The $\alpha 4 \beta 7$ integrin is expressed at low levels in naive B cells but plays an important role in lymphocyte migration into PPs and MLNs. ${ }^{18,27,32}$ MAdCAM-1 on PP-HEVs contributes to both rolling and sticking in these organs. ${ }^{18,31,33}$ The firm arrest of naive $B$ cells in PP HEV is mediated by LFA- 1 and $\alpha 4 \beta 7$, which are activated by CCL21-CCR7. ${ }^{18,23}$ In addition, as in PLNs, naive
B cells can also use CXCR4 and CXCR5 for integrin activation in PPs. ${ }^{25}$

High endothelial venules in MLNs express a mosaic of both peripheral node addressin ${ }^{21}$ and MAdCAM- $1,{ }^{29}$ thus supporting both the PLN-like and PP-like adhesion cascades for lymphocyte homing. ${ }^{21}$

\section{HOMING OF MUCOSAL ANTIBODY-SECRETING CELLS}

When conventional B cells (B2) are activated by T cell-dependent (TD) antigens, i.e., antigens that elicit concomitant "helper" CD4 T-cell responses (usually proteins), they become either ASCs with no proliferative capacity (plasma cells) or memory $\mathrm{B}$ cells $\left(\mathrm{B}_{\mathrm{Mem}}\right)$, which can proliferate and give rise to ASCs (and more $\mathrm{B}_{\mathrm{Mem}}$ ) upon reactivation ${ }^{34}$ (Figure 2). In addition, $\mathrm{B}$ cells responding to $\mathrm{TD}$ antigens participate in germinal center reactions, where they undergo affinity maturation and immuno- 


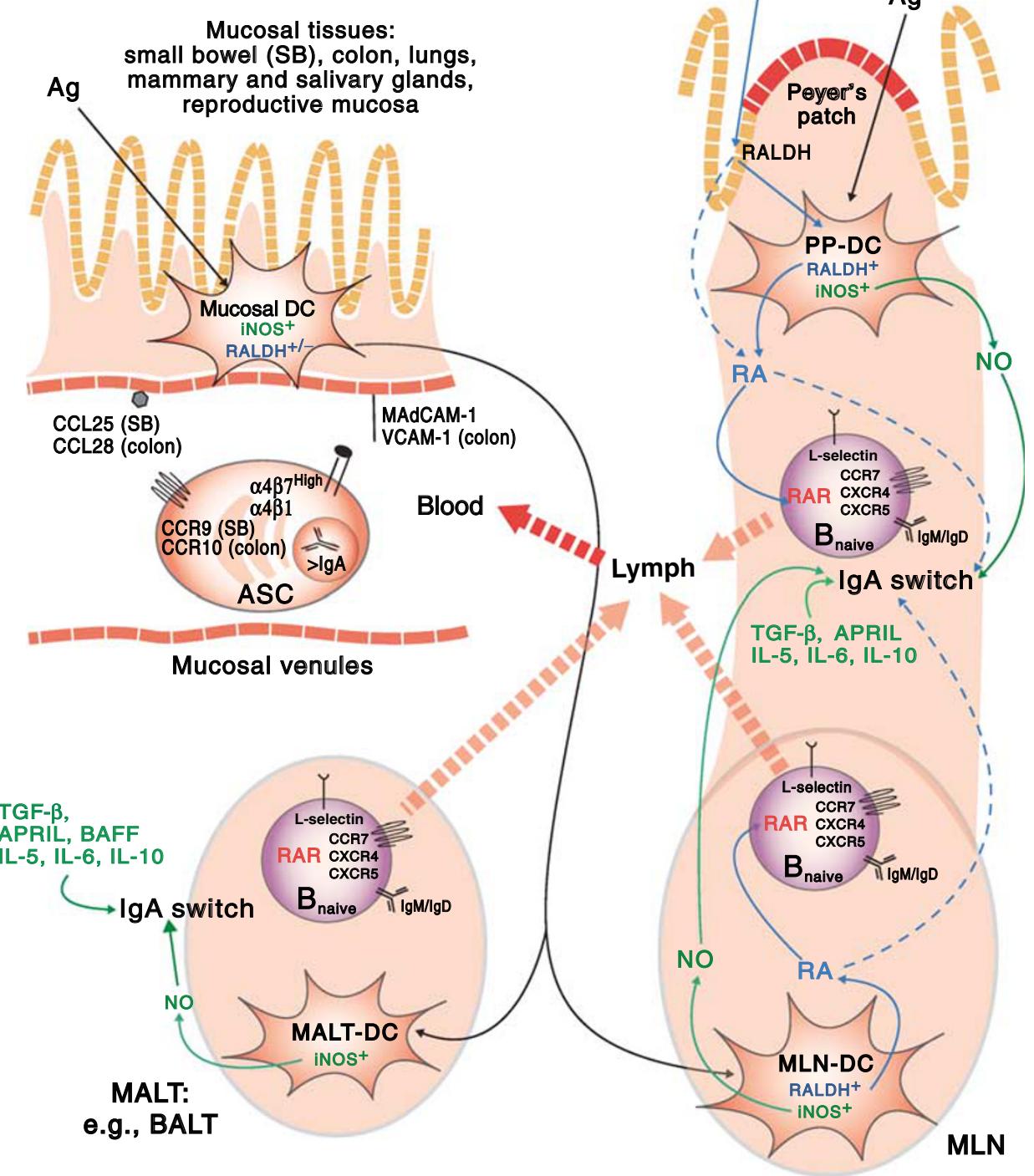

Figure 2 Activation of B cells in MALTs. DCs in peripheral mucosal tissues capture antigens and migrate to their respective draining lymph nodes (MALTs). Intestinal epithelial cells (IEC), as well as DCs in PPs and MLNs (GALT), express retinal dehydrogenase (RALDH) enzymes and therefore have the capacity to metabolize vitamin A from the diet into retinoic acid (RA). RA induces the expression of $\alpha 4 \beta 7$ and CCR9 in ASCs and probably also in $\mathrm{B}_{\mathrm{Mem}}$, endowing them with the capacity to home to the small bowel. In addition, ASCs migrating to mucosal tissues express CCR10, and the CCR10 ligand MEC/CCL28 is expressed in all mucosal compartments. However, it is unknown where, when, and how CCR10 is upregulated on mucosal ASCs. In addition, B cells activated in the MALT microenvironment can switch to IgA-ASCs. IgA responses to TD antigens (e.g., proteins) require CD4 T-cell help and also TGF- $\beta 1$. The cytokines IL-5, IL-6, and IL-10 have also been reported as important for IgA secretion, although they are probably not directly involved in IgA class switching. IgA responses to TI antigens type 1 (e.g., LPS) or type 2 (e.g., bacterial capsule polysaccharides) do not require CD40-CD40L but rely on the cytokine APRIL, which are produced by activated DCs and macrophages. It is noteworthy that the enzyme iNOS, which synthesizes NO, is specifically expressed in MALT-DCs and is critical for both TD and TI IgA responses. In addition, RA also plays a role in promoting the generation of IgA-ASCs in GALT. APRIL, a proliferation-inducing ligand; ASC, antibody-secreting cells; $B_{\text {Mem, }}$ memory B cells; DC, dentritic cell; GALT, gut-associated lymphoid tissue; IEC, intestinal epithelial cell; LPS, lipopolysaccharide; MALT, mucosal-associated lymphoid tissue; NO, nitric oxide ; RA, retinoic acid; RALDH, retinal dehydrogenase; TD, thymus-dependent; TI, thymus-independent.

globulin class switching. ${ }^{34}$ On the other hand, B cells can be activated by $\mathrm{T}$ cell-independent (TI) antigens, either type 1 (polyclonal activators, such as lipopolysaccharide (LPS), CpG, poli-IC) or type 2 (polysaccharides, such as capsular bacterial polysaccharides), and become short-lived IgM-ASCs, except in the peritoneal cavity and the gut mucosa, tissues that can also support TI IgA responses. ${ }^{34}$
Some ASCs producing IgM or IgG (and, to a lesser extent, IgE or IgA) stay in the lymph node medulla or spleen red pulp as short-lived ASCs. ${ }^{35}$ However, most ASCs leave lymphoid tissues and travel to the bone marrow, where a small fraction becomes long-lived plasma cells. ${ }^{35,36}$ CXCR4 and probably also $\alpha 4 \beta 1$, LFA-1, P-selectin ligands, and CD22 are important for ASC lodging retention and/or survival in the bone marrow. ${ }^{37-39}$ 
Some ASCs also home to sites of inflammation; this migration event is probably mediated by CXCR $3 .{ }^{35}$

Peyer's patches are the main secondary lymphoid organs where B cells differentiate into IgA-ASCs ${ }^{40}$ although IgAASCs can also differentiate in MLNs and the peritoneal cavity ${ }^{2}$ (Figure 2). That IgA-ASCs migrate preferentially to the gut was originally described more than 30 years ago. ${ }^{41-43}$ Although the presence of the specific antigen in the target tissue may play a role in the accumulation of IgA-ASCs in the gut (especially in late stages), their initial accumulation in the intestinal lamina propria is clearly antigen-independent, suggesting that it is regulated at the level of cell entry. ${ }^{44,45}$ Indeed, intestinal ASCs express $\alpha 4 \beta 7^{46}$ and this integrin (as well as its ligand MAdCAM$1)$ is critical for the homing of IgA-ASCs to the gut. ${ }^{32}$ In addition, the chemokine receptor CCR10 is expressed on all ASCs located in mucosal compartments, ${ }^{36,47-49}$ and the CCR10 ligand CCL28/MEC is expressed by most mucosal epithelial cells ${ }^{48,50}$ and selectively attracts IgA-ASCs. ${ }^{49,51}$ In fact, IgA-ASCs require CCL28 to home efficiently to the colon lamina propria. ${ }^{52}$ To add even more complexity, a subset of IgA-ASCs also responds to the CCR9 ligand CCL25/TECK, ${ }^{53}$ and ASCs require CCR9 to home to the small intestine, at least in some experimental settings. ${ }^{52,54}$ It is noteworthy that although one report suggested that IgAASCs need both CCR9 and CCR10 for optimal migration to the small bowel, ${ }^{52}$ another study showed that CCR9 and CCR10 play redundant roles in IgA-ASC homing to the small intestine during rotavirus infection. ${ }^{55}$ The reasons for these discrepancies remain to be determined, although it is possible that inflammation upregulates CCL28 in the small bowel, thus making the homing of ASCs less dependent on CCR9.

Homing of IgA-ASCs to the intestinal lamina propria offers an efficient mechanism for locally delivering dimeric IgA that binds to the pIgR expressed on intestinal epithelial cells (IECs) to be finally secreted into the gut lumen. However, it should be considered that serum dimeric IgA can also bind directly to pIgR expressed on hepatocytes, transported to the bile ducts, and secreted via the bile into the gut lumen. ${ }^{56}$ Such a mechanism may, in principle, decrease the relative importance of gut homing on intestinal IgA secretion. However, although hepatobiliary IgA transport is very efficient in mice and rats, it does not play a significant role in humans, which is probably due to species differences in the cellular localization and availability of pIgR, as well as the relative paucity of dimeric IgA in human serum, as compared to mice. ${ }^{56,57}$ Nevertheless, in spite of this potentially compensatory mechanism, memory B cells from $\beta 7$ integrin-deficient mice exhibit a decreased capacity to confer protection against rotavirus infections, ${ }^{7}$ implying that gut homing plays an important role in protective gut IgA responses.

T cell-dependent B-cell responses also generate long-lived $\mathrm{B}_{\mathrm{Mem}}{ }^{34,58}$ It is thought that $\mathrm{B}_{\mathrm{Mem}}$ recirculate through both lymphoid and peripheral tissues, but their migratory behavior has been difficult to study owing to their physiologically low abundance and lack of specific markers in mice. However, $\mathrm{B}_{\mathrm{Mem}}$ conferring protection against intestinal pathogens express $\alpha 4 \beta 7$, indicating that these cells, like their T-cell counterparts, respond to tissue-specific imprinting signals. ${ }^{15,16}$ It is noteworthy that IgA-ASCs have a short half-life in the intestinal mucosa, at least in the steady state, ${ }^{59}$ and whether there are long-lived mucosal plasma cells is still an open question. ${ }^{60}$ Thus, it is likely that IgA-ASCs need to be constantly replenished in the gut by recently activated naive $\mathrm{B}$ cells or $\mathrm{B}_{\mathrm{Mem}}$.

\section{MECHANISMS OF IMPRINTING OF GUT-HOMING B CELLS AND ASC}

A great deal of evidence indicates that the tissue where the antigen is encountered influences the traffic pattern that lymphocytes acquire. For example, pathogens entering through the skin preferentially generate $\mathrm{B}$ and $\mathrm{T}$ lymphocytes with skinhoming receptors. ${ }^{61-65}$ Analogously, oral vaccination induces higher levels of the gut-homing integrin $\alpha 4 \beta 7$ on $\mathrm{B}$ and $\mathrm{T}$ cells than parenteral administration of the same antigen ${ }^{13,14,66-73}$

(Figure 2). The functional relevance of this observation is suggested by the fact that among $\mathrm{B}_{\mathrm{Mem}}$, only $\alpha 4 \beta 7^{+}$(but not $\alpha 4 \beta 7^{\mathrm{Neg}}$ ) cells confer protection against intestinal rotavirus, ${ }^{7,15}$ indicating that gut tropism is required for immune defense against at least some tissue-restricted pathogens.

In the lymphoid microenvironment, dentritic cells (DCs) are essential for efficient T-cell activation. ${ }^{74,75}$ However, DCs can also influence B-cell responses by enhancing their differentiation to ASCs and their survival. ${ }^{76,77}$ It has also been shown that DCs can present unprocessed antigens to $\mathrm{B}$ cells in vivo ${ }^{78-80}$ and affect B-cell function in a tissue-specific fashion. For instance, PP-DCs promote class switching to IgA by activated B cells. ${ }^{81-83}$ Several reports have shown that DCs from PPs and MLNs (gut-associated lymphoid tissue (GALT)-DCs) are sufficient to induce $\alpha 4 \beta 7$ and CCR9 and gut-homing capacity on activated T cells. ${ }^{84-89} \mathrm{We}$ have recently shown that, analogously, GALT-DCs but not DCs from other lymphoid organs imprint gut homing on activated B cells ${ }^{90}$ (Figure 2). Moreover, work from several groups has recently shown that subcapsular macrophages can also present lymph-borne antigens and activate naive B cells in PLNs. ${ }^{91-93}$ It will be interesting to determine whether a similar mechanism operates in MLNs and whether subcapsular macrophages can also imprint tissue-specific homing and/or promote specific IgA class switching in that tissue. In support of this possibility, macrophages can secrete B-cell activating factor (BAFF), ${ }^{76}$ which can induce TI IgA class switching. Furthermore, intestinal lamina propria macrophages were reported to secrete retinoic acid (RA), ${ }^{94}$ which is sufficient to imprint gut homing on activated $\mathrm{B}$ cells ${ }^{90}$ (see below).

What is the molecular mechanism controlling gut homing? Twenty-five years ago, it was shown that malnourished vitamin A-deficient rats exhibit impaired migration of recently activated mesenteric lymphocytes to the intestinal mucosa. ${ }^{95}$ More recently, it was described that vitamin A-deficient rats show a marked decrease in the number of IgA-ASCs and CD4 T cells in the ileum. ${ }^{96}$ However, the molecular basis for these observations was determined only recently in a seminal study by Iwata et al. that showed that mice depleted of vitamin A have a dramatic reduction in the number of effector/memory $\mathrm{T}$ cells in the gut mucosa but not elsewhere. ${ }^{97}$ Concomitant in vitro experiments 
showed that the vitamin A metabolite retinoic acid (RA) is sufficient to induce $\alpha 4 \beta 7$ and CCR9 on activated T cells, even in the absence of DCs. ${ }^{97}$ In agreement with a major role for RA in gut-homing imprinting, blocking RA receptors of the RAR family significantly decreased the induction of $\alpha 4 \beta 7$ by GALTDCs. ${ }^{97}$ Consistently, GALT-DCs, unlike DCs from other tissues, express retinal dehydrogenases (RALDH), which are essential enzymes for RA biosynthesis. ${ }^{97}$

Although GALT-DCs are sufficient to induce gut-homing molecules on lymphocytes in vitro, it is formally possible that other sources of RA may contribute in vivo. For example, IECs express RALDH ${ }^{97}$ and can synthesize RA in vitro. ${ }^{98}$ Also, IECs, and perhaps other cells in the gut, may act as "RA donors" for DCs. In fact, it has been described recently that RA can be passively stored by DCs and used to imprint gut-homing lymphocytes. ${ }^{99}$ Moreover, IP immunization efficiently generates gut-homing $\mathrm{T}$ cells, ${ }^{86,100,101}$ and recently activated $\mathrm{B}$ cells (plasmablasts) may also be imprinted with gut tropism in the peritoneal cavity. ${ }^{102}$ Thus, it is possible that gut-homing lymphocytes can be imprinted in regions other than GALT. Indeed, some nonintestinal viral infections also induce $\alpha 4 \beta 7^{+} \mathrm{T}$ cells ${ }^{103}$ and there may be constitutive sources of RA in the lung mucosa ${ }^{104}$ and liver. ${ }^{105}$ Also, it remains to be determined whether RA synthesis can be induced in nonintestinal tissues under inflammatory or infectious conditions and whether there are additional RA-independent mechanisms of gut-homing imprinting. ${ }^{106}$

It is also unknown how IgA-ASCs are imprinted to home to mucosal compartments other than the small bowel. CCR10 plays a role in IgA-ASC homing to colon, ${ }^{52}$ mammary glands, ${ }^{47}$ and probably other mucosal compartments, ${ }^{49}$ but this chemokine receptor has not been reported to be upregulated in murine $B$ cells in vivo or in vitro, so it is currently unknown where and how CCR10 is induced.

Peritoneal B1 B cells can also give rise to intestinal IgA-ASCs, although the extent of their contribution remains controversial, ranging from 1 to $50 \%$ of all intestinal lamina propria IgA-ASCs, depending on the experimental system and readout. Earlier studies showed that almost half of the IgA-ASCs arise from peritoneal B1 B cells. ${ }^{107,108}$ Consistently, reconstitution experiments with bone marrow from $\mathrm{T}$ cell-deficient mice and peritoneal cavity B1 B cells, as well as mice deficient in B1 B cells, showed that virtually all intestinal lamina propria IgA-ASCs and secretory IgA against commensal flora were of B1 origin, suggesting that these cells account for most of the TI IgA responses, at least in the absence of $\mathrm{T}$ cells. ${ }^{109}$ However, another study showed that, in gnotobiotic mice, conventional B2 B cells contribute most of the bacteria-specific intestinal IgA. ${ }^{110}$ Moreover, in humans, peritoneal B1 B cells do not seem to be a significant source of lamina propria (LP) IgA-ASCs. ${ }^{111}$ Thus, the relative contribution of B1 B cells to the pool of intestinal IgA-ASCs and their relevance to gut immunity remain to be determined.

It is also unknown which traffic molecules B1 cells need to home to the gut mucosa. ${ }^{112}$ It is likely that B1-derived ASCs rely, at least in part, on the same homing imprinting mechanisms as B2-derived IgA-ASCs. A recent study showed that the peritoneal cavity environment can "instruct" B1 and B2 B cells to home back to the peritoneum via induction of CXCR5 expression, ${ }^{102}$ which is critical for lodging of B1 B cells in body cavities. ${ }^{113}$ Interestingly, the peritoneal environment also imprinted gut-homing capacity and IgA class switching/secretion on plasmablasts. ${ }^{102}$ It remains to be determined whether this "peritoneal imprinting" relies on similar mechanisms such as GALT imprinting. In addition, TLR ligands also play an important role during peritoneal B1 B-cell mobilization by transiently downregulating integrin expression on B1 cells. ${ }^{114}$

Can B cells change or modulate their homing potential? We and others have shown that gut- or skin-homing $\mathrm{T}$ cells can be "reprogrammed" in their migratory potential. Skin-homing T cells can be converted to gut-homing $\mathrm{T}$ cells and vice versa if they are stimulated with or without GALT-DCs or RA, respectively. ${ }^{88,89}$ Similarly, human B cells may also exhibit homing plasticity, ${ }^{73}$ and we have shown that they can be re-educated and acquire or lose gut-homing potential when they are restimulated with or without RA, respectively ${ }^{90}$ (Figure 3). Given that terminally differentiated plasma cells do not divide, it is likely that homing plasticity occurs at the level of $\mathrm{B}_{\mathrm{Mem}}$. Also, $\mathrm{B}_{\mathrm{Mem}}$ expressing either IgM or another immunoglobulin isotype different from IgA may switch to IgA when reactivated in mucosal-associated lymphoid tissues (MALTs). In fact, sequential immunoglobulin switching from IgG2b to IgA or, in humans, from IgA1 to IgA2, has been described. ${ }^{115}$ On the other hand, $\operatorname{Ig} \mathrm{A}^{+} \mathrm{B}_{\mathrm{Mem}}$ remain $\operatorname{Ig} \mathrm{A}^{+}$regardless of where they are reactivated, although, given their homing plasticity, ${ }^{90}$ they probably lose their gut-tropic capacity when reactivated in a nonintestinal context outside GALT.

\section{DIFFERENTIATION OF IgA-ASC IN MUCOSALTISSUES: MALTS VS. GALT}

Peyer's patches were the first secondary lymphoid organs proposed as an inductive site for IgA-ASCs. ${ }^{40}$ Hallmark molecular markers of immunoglobulin class switching, such as activationinduced cytidine deaminase (AID, essential for immunoglobulin class switching ${ }^{116}$ ), and specific markers for IgA class switching, such as germline alpha transcripts and postswitch circular DNA transcripts, ${ }^{117}$ are found at much higher levels in PPs as compared to MLNs and the peritoneal cavity. ${ }^{118}$ In addition, IgA class switching is also higher in PPs as compared to the nasal-associated lymphoid tissues or bronchus-associated lymphoid tissues. ${ }^{119}$ It is noteworthy that IgA class switching has also been reported in human and murine colon lamina propria $^{115,120}$ as well as in murine small intestinal lamina propria. ${ }^{121}$ However, other studies have failed to find molecular markers of IgA class switching in the small intestinal lamina propria of mice or humans, ${ }^{118,122,123}$ arguing against a significant role of in situ IgA class switching in this compartment. In this regard, it should be considered that IgA class switching also takes place in the isolated lymphoid follicles (ILF) of the small intestine, which could contaminate lamina propria preparations. ${ }^{123}$ However, ILF do not seem to efficiently generate IgA responses against orally administered antigens. ${ }^{124,125}$

Several different and sometimes seemingly contradictory pathways have been implicated for inducing IgA-ASCs 


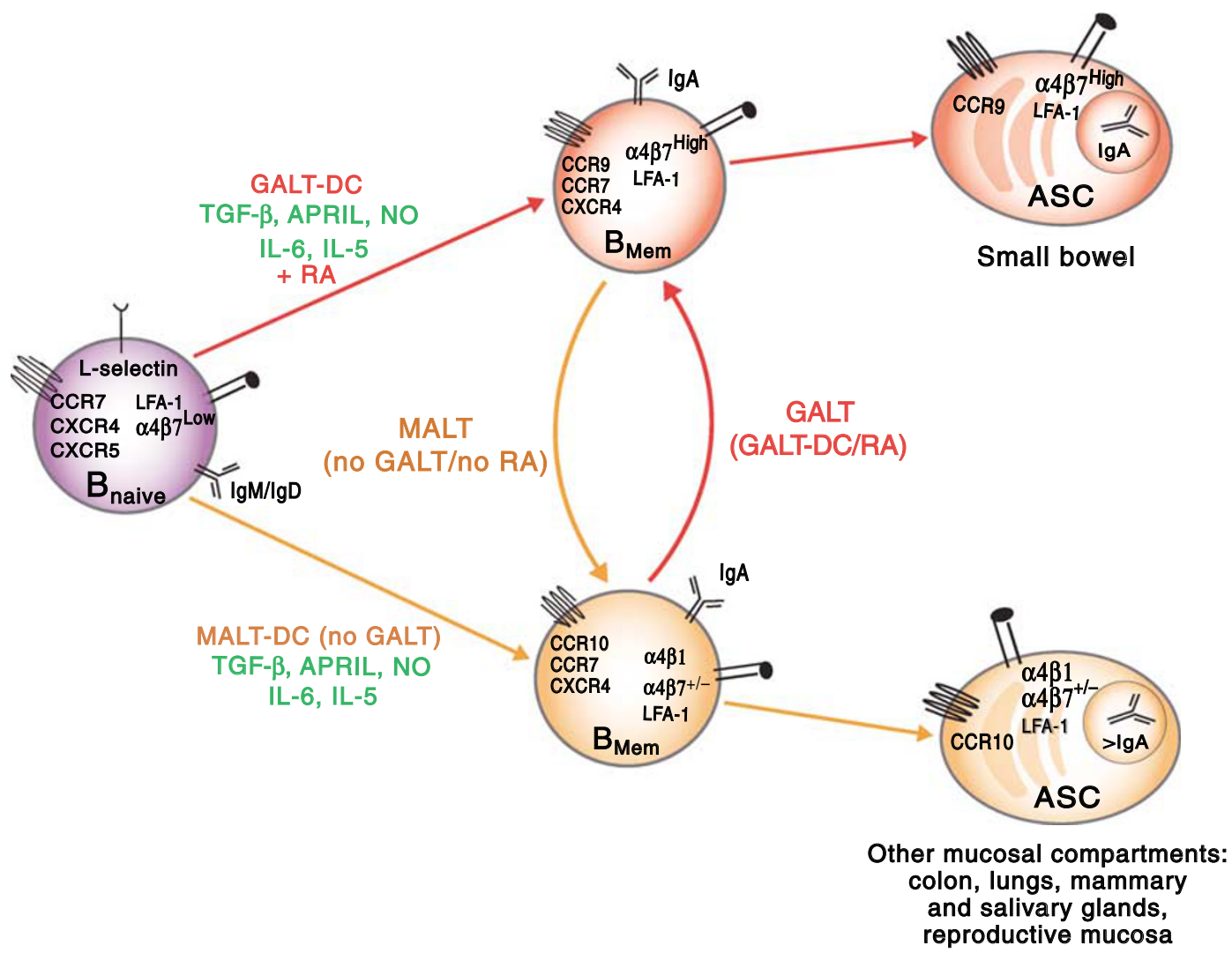

Figure 3 Plasticity in lymphocyte homing. B cells show plasticity regarding their homing commitment. As ASCs are terminally differentiated and do not divide, it is likely that the capacity to be reprogrammed in their homing potential resides at the level of $B_{\text {Mem }}$. If activated $B$ cells that do not express guthoming receptors are restimulated in the presence of $R A$, they readily upregulate $\alpha 4 \beta 7$ and CCR9. On the other hand, $B$ cells with gut-homing capacity lose $\alpha 4 \beta 7$ and CCR9 if they are reactivated without RA. It is possible that $\lg A^{N e g} B_{\text {Mem }}$ give rise to $\lg A-A S C s$ and $\lg A^{+} B_{\text {Mem }}$ upon restimulation in the MALTs. However, gut-homing $\lg \mathrm{A}^{+} \mathrm{B}_{\mathrm{Mem}}$, restimulated outside the MALTs, remain $\lg \mathrm{A}^{+}$, although they lose their gut-homing capacity. The latter may be a potential mechanism to help targeting IgA ${ }^{+} B_{M e m}$ and IgA-ASCs to mucosal tissues outside the gut. ASC, antibody-secreting cells; $B_{\text {Mem, }}$ memory $B$ cells; MALT, mucosal-associated lymphoid tissue.

at mucosal tissues (Table 1). The in vivo interplay and the relative roles of these mechanisms are probably determined by the context in which $B$ cells are activated, e.g., the nature of the antigen, $\mathrm{T}$ cell help, site of activation, type of responder $\mathrm{B}$ cells (B1 or B2), and the contribution of Toll-like signals. In addition, as discussed below, the experimental conditions used may also have a significant impact in the final readout.

\section{Role of TGF- $\beta 1$}

IgA responses to TD antigens require transforming growth factor (TGF)- $\beta 1$, as well as CD4 T-cell "help," the latter provided in the form of CD40L as well as cytokines such as IL-5 (Figure 4A). TGF- $\beta$ is critical for IgA responses in vivo, as TGF- $\beta 1$ knockout mice have impaired systemic and mucosal IgA responses. ${ }^{126}$ Moreover, mice whose B cells are deficient in TGF- $\beta$ RII lack serum $\operatorname{IgA}^{127}$ and do not mount systemic ${ }^{127}$ or mucosal ${ }^{128}$ antigen-specific IgA responses. Consistently, mice with $\mathrm{B}$ cells deficient in Smad2, which is critically involved in TGF- $\beta$ signaling, show decreased levels of serum IgA and have impaired antigenspecific IgA responses. ${ }^{129}$ In addition, the cytokines IL- $5^{130-133}$ and IL-6 $6^{134-138}$ fulfill a complementary role in IgA production by promoting differentiation of ASCs and IgA secretion. Indeed, IgA levels are increased in mice overexpressing IL-6, ${ }^{139}$ and
IL-5 plays also an additional indirect role in IgA production by promoting B1 B-cell differentiation. ${ }^{140-143}$

Although TGF- $\beta$ plays a central role in the differentiation of IgA-ASCs, the relevant sources of TGF- $\beta$ in the gut are less clear. TGF- $\beta 1 \mathrm{mRNA}$ and/or protein have been detected in rodent jejunal enterocytes, ${ }^{144}$ small and large bowel intestinal epithelium, ${ }^{145}$ and intestinal lamina propria cells ${ }^{145,146}$ (Figure 4A). However, TGF- $\beta 1$ mRNA and protein are expressed at very low quantities in the steady-state noninflamed human intestine and become upregulated only during inflammation, e.g., in active inflammatory bowel disease. ${ }^{146,147}$ It is noteworthy that TGF- $\beta$ mRNA transcripts have been detected in PP-DCs and $\mathrm{CD} 103^{+}$ MLN-DCs. ${ }^{148,149}$ Moreover, CD103 ${ }^{+}$MLN-DCs and LP-DCs have been described to secrete active TGF- $\beta$, as evidenced by their capacity to induce foxp $3^{+} \mathrm{T}_{\mathrm{REG}}$, which is abrogated by blocking TGF- $\beta .^{94,149}$ However, parallel studies by others showed that TGF- $\beta 1$ needed to be added exogenously to obtain a significant induction of $\mathrm{T}_{\mathrm{REG}}$ in this system, ${ }^{150,151}$ suggesting that LPDCs and MLN-DCs are not a significant source of active TGF- $\beta 1$ in the gut. Thus, the actual contribution of gut-associated DCs to the pool of active TGF- $\beta 1$ needs further clarification. An additional possibility is that gut-associated DCs are in charge of activating latent TGF- $\beta 1$. In this regard, it has been shown that the 
Table 1 Mechanisms involved in IgA-ASC differentiation in GALTs

\begin{tabular}{|c|c|c|c|c|c|c|c|c|}
\hline & TD & $\mathrm{TI}$ & Effect in vitro & Effect in vivo & $\begin{array}{l}\text { IgA class } \\
\text { switching }^{a}\end{array}$ & $\begin{array}{l}\text { ASC differ- } \\
\text { entiation IgA } \\
\text { secretion }\end{array}$ & $\begin{array}{l}\text { Role in other } \\
\text { MALTs }^{b}\end{array}$ & References \\
\hline TGF- $\beta 1$ & $\uparrow$ & $-?$ & $\uparrow o r \downarrow c$ & $\uparrow$ & $\uparrow$ & - or $\downarrow$ & $\uparrow$ & $\begin{array}{l}126-128 \\
153-160\end{array}$ \\
\hline iNOS/NO & $\uparrow$ & $\uparrow$ & $\uparrow$ & $\uparrow$ & $\uparrow^{d}$ & - & $\uparrow$ & 161 \\
\hline APRIL & - & $\uparrow$ & $\uparrow$ & $\uparrow$ & $\uparrow$ & - & $\uparrow ?$ & $\begin{array}{l}115,164,165 \\
167-169\end{array}$ \\
\hline BAFF & - & $\uparrow$ & $\uparrow$ & $\uparrow ?$ & $\uparrow$ & - & $\uparrow ?$ & $164-169$ \\
\hline RA & $\uparrow ?$ & $\uparrow$ & $\uparrow$ & $\uparrow e$ & $\uparrow ?$ & $?$ & - & $\begin{array}{l}90,176-178 \\
180-182\end{array}$ \\
\hline $\begin{array}{l}\text { IL-5, IL-6, } \\
\text { IL-10 }\end{array}$ & $\uparrow$ & $\uparrow^{\dagger}$ & $\uparrow$ & $\uparrow$ & - & $\uparrow$ & $\uparrow$ & $\begin{array}{l}90,130-139 \\
153\end{array}$ \\
\hline VIP & $\uparrow ?$ & $\uparrow ?$ & $\uparrow$ & $\uparrow ?$ & $\uparrow$ & $?$ & - & $171-173$ \\
\hline
\end{tabular}

APRIL, a proliferation-inducing ligand; ASC, antibody-secreting cell; BAFF, B-cell activating factor; GALT, gut-associated lymphoid tissue; iNOS, inducible nitric oxide synthase; NO, nitric oxide; RA, retinoic acid; TD, thymus-dependent; TI, thymus-independent; VIP, vasoactive intestinal peptide.

aThe effect can be direct or indirect in IgA class switching.

bIncludes lymphoid tissues associated with bronchus (BALT), mammary and salivary glands, and reproductive mucosa.

cWhether TGF- $\beta 1$ increases or decreases the generation of IgA-ASCs in vitro depends on the culture conditions (discussed in the text).

diNOS/NO indirectly promotes TD and TI IgA class-switching by increasing B-cell responsiveness to TGF- $\beta 1$ and by inducing APRIL and BAFF secretion by DCs, respectively.

eRA increases IgA-ASCs in the gut by imprinting gut homing and by promoting IgA-ASC differentiation.

fSince IL-5 is produced by T cells, this cytokine is probably more relevant for TD IgA responses.

${ }^{\uparrow}$ Promotes IgA-ASC differentiation; ${ }^{\downarrow}$ decreases IgA-ASC differentiation; — not demonstrated effect on IgA-ASC differentiation; ? effect unclear; TD/TI thymus-dependentindependent B-cell responses.

integrin $\alpha \mathrm{v} \beta 8$ is expressed on DCs and that it is critical to activate TGF- $\beta$ in vivo, ${ }^{152}$ suggesting yet another potential mechanism by which gut-associated DCs (as well as DCs from other mucosal tissues) may promote IgA class switching.

While the essential in vivo role of TGF- $\beta$ in IgA class switching is well demonstrated, its in vitro effects on IgA class switching/secretion seem to vary significantly depending on the experimental system. For instance, although TGF- $\beta 1$ consistently induces IgA production in LPS-activated splenocytes, ${ }^{153}$ it suppresses the spontaneous IgA secretion by nonstimulated mononuclear cells from MLNs and PPs and almost completely blocks IL-5-induced IgA secretion in LPS-activated bulk splenocytes. ${ }^{90,153}$ Paradoxically, TGF- $\beta 1$ potentiates IL-5-induced IgA secretion in T cell-depleted MLN cells activated by LPS. ${ }^{154,155}$ Interestingly, the timing of IL-5 addition seems to be important in whether or not IL- 5 synergizes with TGF- $\beta 1$ for IgA secretion. ${ }^{156}$ Moreover, TGF- $\beta 1$ can only be present during the initial phase of in vitro human B-cell cultures, because it inhibits IgA secretion at later stages. ${ }^{157}$ Nonetheless, it has been demonstrated that TGF- $\beta 1$ can truly promote IgA class switching at the clonal level, ${ }^{158,159}$ whereas IL-5 is mostly involved in post-

switch differentiation/secretion. ${ }^{155}$ Finally, while TGF- $\beta 1$ promotes molecular IgA class switching regardless of the activation stimuli, IgA secretion is induced only when B cells are activated with LPS but not by B-cell antigen receptor (BCR) crosslinking. ${ }^{160}$ Thus, TGF- $\beta 1$ may have very different and even opposite effects on IgA production/secretion depending on seemingly minor differences in culture conditions, which may account, at least in part, for some discrepant reports on the role of TGF- $\beta 1$ and IL-5 in IgA class-switching/secretion. ${ }^{90,153}$
In summary, TGF- $\beta 1$ promotes germ-line IgA class switching and is essential for TD IgA responses in vivo. However, it may block ASC differentiation and IgA secretion in some in vitro settings. On the other hand, IL- 5 and IL- 6 are probably not directly involved in IgA class switching, but they contribute to ASC differentiation and immunoglobulin secretion (including $\operatorname{Ig} \mathrm{A}$ ), thus complementing the role of TGF- $\beta 1$.

\section{Role of nitric oxide}

It was recently described that nitric oxide (NO) plays a critical role in IgA class switching and in the generation of IgAASCs $^{161}$ (Figure 4). Mice deficient in the inducible isoform of nitric oxide synthase (iNOS) had a marked reduction in serum and intestinal IgA, but not in other immunoglobulin isotypes. A similar effect on IgA levels was observed when mice were treated with NO scavengers. It is noteworthy that iNOS was critical for both TD and TI IgA responses. TD IgA responses were affected because iNOS-deficient mice expressed decreased levels of TGF- $\beta$ RII and Smad proteins on B cells. ${ }^{161}$ In addition, NO probably also affects DC function, as iNOS-deficient GALT-DCs had a significantly reduced capacity to produce APRIL (a proliferation-inducing ligand) and BAFF (B-cell activating factor/Blys), which may explain the lack of TI IgA responses (discussed below). Interestingly, iNOS expression is dependent on commensal flora and TLR signals, because DC from germ-free or MyD88 ${ }^{-/-}$mice express very low levels of this enzyme. ${ }^{161} \mathrm{In}$ addition, given that serum IgA levels in iNOS knockout mice can be rescued by adoptively transferring wild-type LP-DCs, ${ }^{161}$ iNOS expression by mucosal DCs ${ }^{161}$ seems to be sufficient to allow IgA class switching/secretion. However, these results do 
a IEC

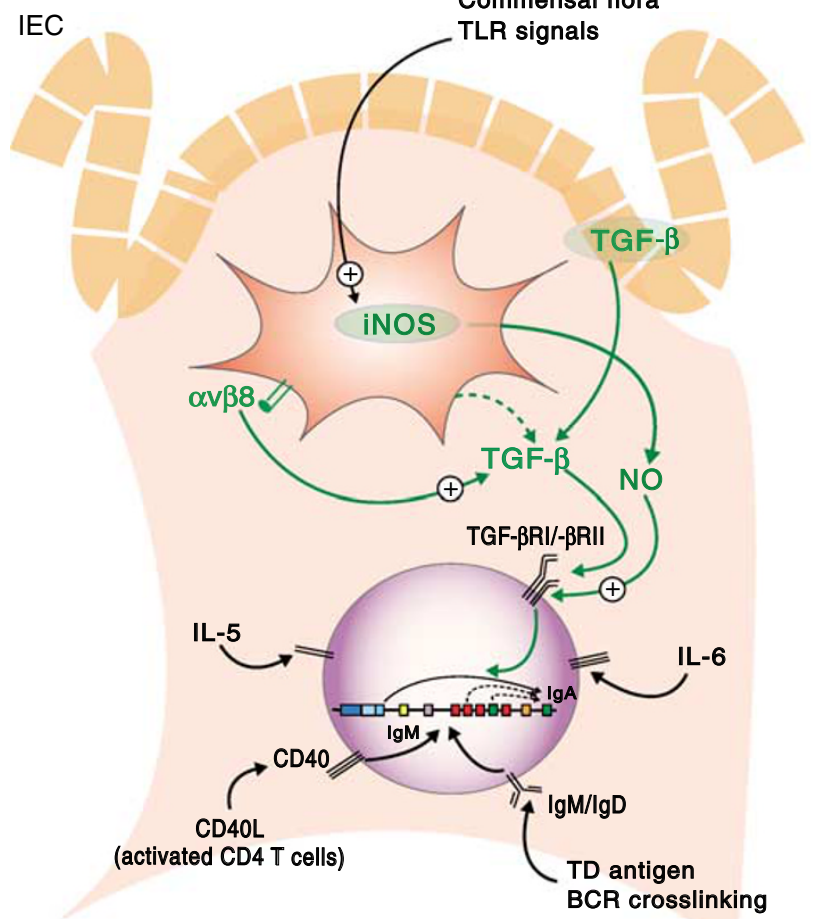

b IEC

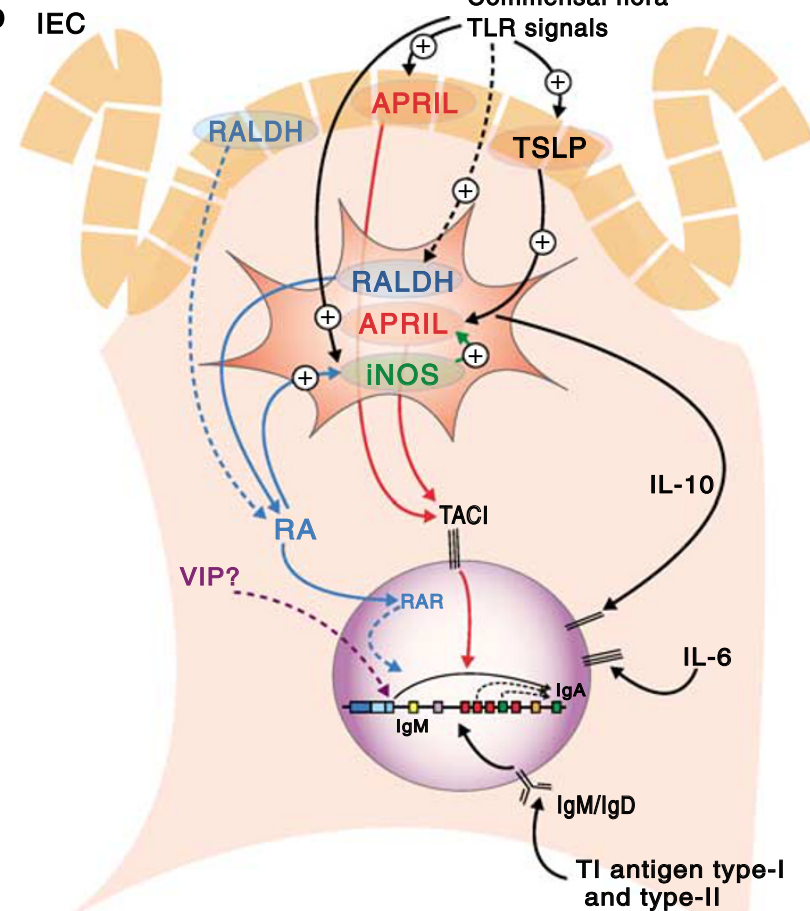

Figure 4 Mechanisms inducing IgA class switching in GALT. IgA class switching is a complex process. (a) IgA responses to TD antigens require interaction between CD40-CD40L (the latter expressed by activated CD4 T cells) and also TGF- $\beta 1$. IECs and GALT-DCs are among the potential sources of TGF- $\beta 1$ in the gut mucosa. DCs also express the integrin $\alpha \mathrm{v} \beta 8$, which is essential for TGF- $\beta 1$ activation in vivo. (b) Gut IgA responses to $\mathrm{TI}$ antigens require APRIL binding to TACI on $\mathrm{B}$ cells. APRIL is produced by IEL upon stimulation by commensal flora or TLR signals. These stimuli also induce TSLP secretion by IEL, which in turn induces more APRIL expression by GALT-DCs. IECs and GALT-DCs can also metabolize vitamin A into RA. The latter imprints gut-homing lymphocytes, but in concert with IL-5 or IL-6, can also induce differentiation of IgA-ASCs. RA may induce IgA class switching directly or by upregulating iNOS and TGF- $\beta$ secretion. VIP can also induce TGF- $\beta$-independent IgA class switching in vitro, although its significance in vivo remains to be determined. Mucosal DCs (including GALT-DCs) express the inducible form of iNOS, which is induced by commensal flora and TLR signals. iNOS generates NO, which is critical for both TD and TI IgA responses. Indeed, NO synthesis is essential for proper TGF- $\beta 1$ signaling on B cells and also for APRIL synthesis by GALT-DCs. Interestingly, IgA class switching can start from naive IgM-expressing B cells or sequentially after IgG class switching or, in humans, IgA1 class switching (the latter generates protease-resistant IgA2). Dotted lines: not clearly demonstrated. (+): synthesis induction or activation. APRIL, a proliferation-inducing ligand; ASC, antibody-secreting cells; DC, dentritic cell; GALT, gutassociated lymphoid tissue; IEC, intestinal epithelial cell; IEL, intraepithelial lymphocytes; iNOS, inducible nitric oxide synthase; NO, nitric oxide; TACI, transmembrane activator and CAML interactor; TD, thymus-dependent; TI, thymus-independent; TSLP, thymus stromal lymphopoietin; VIP, vasoactive intestinal peptide.

not exclude the possibility that NO secretion by other cells in the gut may also contribute to or be sufficient for sustaining IgA production. Also, although iNOS is necessary for IgA induction by GALT-DCs, ${ }^{161}$ it has not been shown whether its expression is sufficient to confer IgA-inducing capacity to nonmucosal DCs.

\section{APRIL and BAFF}

As discussed above, in addition to TD IgA responses to proteins, B cells can respond to TI antigens. A fraction of TI IgA-ASCs derives from B1 B cells. In fact, in contrast to conventional B2 B cells, B1 $\mathrm{B}$ cells do not seem to require BCR stimulation to become IgAASCs. ${ }^{162}$ However, the production of "natural" TI intestinal IgA against commensal flora requires the presence of PPs or MLNs, as shown in mice deficient in LN and GALT (alymphoplasia aly/aly mice) reconstituted with wild-type bone marrow, which lack intestinal IgA. ${ }^{163}$ It is noteworthy that serum IgA is present in aly/aly mice, which lack intestinal IgA indicating that extraintestinal IgA switching can occur in the absence of GALT and PLN. ${ }^{163}$
It has been determined that the cytokine APRIL is important for the induction of TI IgA-ASCs (Figure 4B). APRIL knockout mice show decreased mucosal TI IgA responses, and both APRIL and BAFF are sufficient to induce CD40-independent IgA class switching on murine naive B2 B cells, even without BCR stimulation, ${ }^{164,165}$ although in this case, either TGF- $\beta 1$, IL-4, or IL-10 need to be supplemented to the cultures. ${ }^{167}$ APRIL and BAFF bind to the receptor TACI (transmembrane activator and CAML interactor), and TACI (but not BAFF-R) is essential for induction of IgA class switching by APRIL and BAFF in murine and human B cells. ${ }^{164,165,169}$ However, although both APRIL and BAFF can induce IgA class switching in vitro, BAFF-deficient mice show only a mild decrease in IgA (despite a significant decrease in most other immunoglobulin isotypes), ${ }^{166}$ which is consistent with a major role of APRIL-TACI but not BAFF-TACI interactions in IgA class-switching in vivo. It is noteworthy that IgA induction by TGF- $\beta 1$ plus LPS is largely TACI- and BAFF-R-independent. ${ }^{165}$ In fact TACI-deficient mice have impaired TI but normal TD IgA immune responses ${ }^{168}$ (Table 1). 
BAFF and APRIL are expressed by cytokine- or TLR-activated DCs and monocytes, endowing them with the capacity to induce TI IgA class switching. ${ }^{167}$ APRIL is also induced in IECs by commensal flora and TLR signals, especially in the distal part of the intestine $^{115}$ (Figure 4B). TLR signals also stimulate the production of the cytokine thymus stromal lymphopoietin (TSLP) by IECs, which in turn induces APRIL and IL-10 secretion by LPDCs, further contributing to their IgA-inducing capacity. ${ }^{115}$

In human B cells, BAFF preferentially induces IgA1, while APRIL induces IgA2 (but not IgA1) class switching. ${ }^{115,167}$ In addition, APRIL induces IgA2 class switching starting from either IgM or sequentially from IgG1 or IgA 1 class-switched cells. ${ }^{115}$ The latter may represent a mechanism by which IgA1 induced in PP germinal centers becomes more resistant to intestinal proteases by switching locally to $\operatorname{Ig} \mathrm{A} 2$ in the colon lamina propria. ${ }^{115}$ It is noteworthy that TACI is mutated in some common variable immunodeficiencies as well as in some isolated IgA immunodeficiencies, underscoring the relevance of IgAinducing mechanisms in human pathologies. ${ }^{170}$

\section{Vasoactive intestinal peptide}

Vasoactive intestinal peptide (VIP), which is highly expressed in postsynaptic parasympathetic nerve fibers and intrinsic neurons in the intestinal lamina propria, induces IgA1 and IgA2 secretion in anti-CD40-stimulated human B cells in a TGF- $\beta$-independent fashion ${ }^{171-173}$ (Figure 4B). In fact, TGF- $\beta 1$, as well as several other cytokines, did not induce IgA in this system, ${ }^{173}$ illustrating yet another example of the variable effect of TGF- $\beta 1$ on IgA secretion in vitro. Interestingly, VIP may also indirectly contribute to IgA secretion by inducing nitric oxide synthase activity and NO production. ${ }^{174,175}$ It remains to be determined whether VIP plays a physiological role in IgA secretion and how it might influence other pathways that induce IgA secretion in the gut.

\section{Role of GALT-DCs and RA}

In addition to their imprinting effect on gut-homing $\mathrm{T}$ and B cells, ${ }^{85,86,90}$ GALT-DCs can efficiently induce IgA-ASCs in vitro. ${ }^{81-83,90}$ Moreover, GALT-DCs can induce IgA secretion by BCR-stimulated B cells independent of T cells, ${ }^{90}$ as has been shown in other settings. ${ }^{109}$ This effect may be mediated, at least in part, by their capacity to produce active TGF- $\beta 1^{94,148,149,152}$ and secrete APRIL. ${ }^{115}$ However, GALT-DCs (and LP-DCs) can also induce and/or contribute to IgA class switching/secretion by secreting RA (Figure 4B). RA induces IgA secretion in LPS-activated splenocytes. ${ }^{176}$ Interestingly, although RA also induces TGF- $\beta$ activity in LPS-activated splenocytes, ${ }^{176-178}$ the IgA-inducing effect of RA is only partially dependent on this cytokine. ${ }^{176}$ Instead, RA-induced IgA secretion requires either T cells or exogenous IL- $5,{ }^{180}$ and IL-5 is also essential for RA-induced IgA switching in LPS-activated splenocytes. ${ }^{181}$ Moreover, GALT-DC require RA and IL-6 for optimal IgA induction in vitro. ${ }^{83,90}$ Interestingly, RA and IL-6 (and/or IL-5) can also synergize to induce IgA secretion in human B cells. ${ }^{90}$ Thus, by inducing gut-homing potential and IgA secretion, RA links lymphocyte migration and function in the gut. ${ }^{90,112}$
Consistent with the effect of RA on IgA secretion in vitro, oral administration of an RA-receptor agonist significantly increases serum IgA levels in rats. ${ }^{182}$ Moreover, treatment with either RA or an RA receptor agonist potentiates LPS-induced iNOS expression in several organs and also increases plasma levels of nitrate/nitrite in rats. ${ }^{183,184}$ Of note, the iNOS gene promoter has an RA response element that is directly activated by RA bound to its nuclear RAR $\alpha /$ RXR heterodimeric receptor. ${ }^{184,185}$ As discussed above, iNOS expression is critical for the in vivo production of IgA. Thus, in addition to increasing IgA class switching, RA may indirectly contribute to IgA secretion by inducing iNOS expression.

Precursors of retinoids ( $\beta$-carotene and retinyl esters) in the diet are absorbed from the gut lumen and can be converted to RA in IECs ${ }^{98}$ and DCs near the germinal centers in PPs. ${ }^{97}$ This proximity could explain the predominant IgA class switching observed in PPs as compared to MLNs. ${ }^{118}$ Consistent with a role of vitamin A in gut IgA production, rats depleted of vitamin A have decreased levels of total IgA in intestinal lavages and decreased mucosal antigen-specific IgA responses. ${ }^{186-190}$ Also, vitamin A-depleted mice show impaired IgA secretion and protection at mucosal sites, ${ }^{191,192}$ as well as impaired IgA responses to oral toxins. ${ }^{193}$ However, it should be kept in mind that vitamin A deficiency may have other effects on the immune system. In fact, the greater susceptibility to intestinal infections and toxins observed in these animals may also be explained, at least in part, by decreased pIgR expression and therefore decreased IgA secretion to the gut and other mucosal compartments. ${ }^{186,190,192}$ Moreover, although vitamin A-deficient mice have a greatly reduced number of IgA-ASCs in the small bowel, ${ }^{90,96}$ they have normal serum IgA levels, ${ }^{90}$ indicating that retinoids are not absolutely required for IgA production in other tissues.

In summary, given the critical role of RA in T- and B-cell guthoming imprinting, ${ }^{90,97}$ as well as its IgA-ASC-promoting potential in the gut, ${ }^{90,176}$ it is not surprising that vitamin A deficiency is associated with impaired intestinal immune responses ${ }^{186-194}$ and increased mortality. ${ }^{195}$ Moreover, vitamin A supplementation correlates with a significant decrease in diarrhea and mortality in HIV-infected or malnourished children. ${ }^{196-199}$

\section{CONCLUSION}

Although our understanding of the mechanisms inducing IgAASC homing to the small bowel has increased significantly, it is still unknown how IgA-ASCs are imprinted to migrate to other mucosal compartments, such as colon, lungs, and salivary and mammary glands. In this regard, the chemokine receptor CCR 10 has been proposed as a "common" mucosal homing receptor for IgA-ASCs. However, where and how CCR10 is induced is still a mystery. It is also unclear to what extent $\mathrm{B} 1 \mathrm{~B}$ cells contribute to the generation of gut IgA-ASCs and whether they obey the same gut-homing imprinting signals as conventional B2 B cells.

As we have discussed, IgA class switching and differentiation of IgA-ASCs is a complex process. TGF- $\beta 1$ and $\mathrm{iNOS} / \mathrm{NO}$ play a critical role in the generation of IgA-ASCs in vivo. However, in the gut mucosa, other mechanisms may work independently of or in complement to TGF- $\beta 1$ to generate IgA-ASCs. 
APRIL-TACI interactions can induce TGF- $\beta 1$-independent and TI IgA class switching in the intestine. In addition, both VIP and RA also induce TGF- $\beta 1$-independent IgA class switching. Therefore, it will be important to determine the relative in vivo contributions and interrelationships among all these IgAinducing mechanisms. A systematic dissection of each pathway in different settings of B-cell activation (e.g., TD, TI, mucosal, systemic, with and without TLR signals) will be required to sort out these questions.

\section{ACKNOWLEDGMENTS}

We are grateful to Susan Davis for valuable editorial assistance and to Drs Scott Snapper and Andrea Cerutti for critical reading of this manuscript. JRM is indebted to Ingrid Ramos for constant support. JRM is supported by grants from Crohn's \& Colitis Foundation of America (CCFA), Cancer Research Institute (CRI) and Center for the Study of Inflammatory Bowel Disease (CSIBD, DK43351). UHvA is supported by grants from the $\mathrm{NIH}$.

\section{DISCLOSURE}

The authors declared no conflict of interest.

\section{2008 Society for Mucosal Immunology}

\section{REFERENCES}

1. Suzuki, K., Ha, S.A., Tsuji, M. \& Fagarasan, S. Intestinal IgA synthesis: a primitive form of adaptive immunity that regulates microbial communities in the gut. Semin. Immunol. 19, 127-135 (2007).

2. Macpherson, A.J. \& Slack, E. The functional interactions of commensal bacteria with intestinal secretory IgA. Curr. Opin. Gastroenterol. 23, 673-678 (2007).

3. Lycke, N., Erlandsson, L., Ekman, L., Schon, K. \& Leanderson, T. Lack of $J$ chain inhibits the transport of gut IgA and abrogates the development of intestinal antitoxic protection. J. Immunol. 163, 913-919 (1999).

4. Wijburg, O.L. et al. Innate secretory antibodies protect against natural Salmonella typhimurium infection. J. Exp. Med. 203, 21-26 (2006).

5. Uren, T.K. et al. Vaccine-induced protection against gastrointestinal bacterial infections in the absence of secretory antibodies. Eur. J. Immunol. 35, 180-188 (2005).

6. Mbawuike, I.N. et al. Mucosal immunity to influenza without IgA: an IgA knockout mouse model. J. Immunol. 162, 2530-2537 (1999).

7. Kuklin, N.A. et al. Protective intestinal anti-rotavirus B cell immunity is dependent on alpha 4 beta 7 integrin expression but does not require IgA antibody production. J. Immunol. 166, 1894-1902 (2001).

8. Corthesy, B. Roundtrip ticket for secretory IgA: role in mucosal homeostasis? J. Immunol. 178, 27-32 (2007).

9. Brandtzaeg, P., Carlsen, H.S. \& Halstensen, T.S. The B-cell system in inflammatory bowel disease. Adv. Exp. Med. Biol. 579, 149-167 (2006).

10. Sait, L.C. et al. Secretory antibodies reduce systemic antibody responses against the gastrointestinal commensal flora. Int. Immunol. 19, 257-265 (2007).

11. Macpherson, A.J. \& Uhr, T. Induction of protective IgA by intestinal dendritic cells carrying commensal bacteria. Science 303, 1662-1665 (2004).

12. Latiff, A.H. \& Kerr, M.A. The clinical significance of immunoglobulin $A$ deficiency. Ann. Clin. Biochem. 44, 131-139 (2007).

13. Youngman, K.R. et al. Correlation of tissue distribution, developmental phenotype, and intestinal homing receptor expression of antigenspecific $B$ cells during the murine anti-rotavirus immune response. J. Immunol. 168, 2173-2181 (2002).

14. Gonzalez, A.M. et al. Rotavirus-specific B cells induced by recent infection in adults and children predominantly express the intestinal homing receptor alpha4beta7. Virology 305, 93-105 (2003).

15. Williams, M.B. et al. The memory B cell subset responsible for the secretory IgA response and protective humoral immunity to rotavirus expresses the intestinal homing receptor, alpha4beta7. J. Immunol. 161, 4227-4235 (1998).

16. Weitkamp, J.H. et al. VH1-46 Is the dominant immunoglobulin heavy chain gene segment in rotavirus-specific memory $\mathrm{B}$ cells expressing the intestinal homing receptor \{alpha\}4\{beta\}7. J. Immunol. 174, 3454-3460 (2005).
17. Rodrigo Mora, J. \& von Andrian, U.H. Specificity and plasticity of memory lymphocyte migration. Curr. Top. Microbiol. Immunol. 308, 83-116 (2006).

18. Bargatze, R.F., Jutila, M.A. \& Butcher, E.C. Distinct roles of L-selectin and integrins a4b7 and LFA-1 in lymphocyte homing to Peyer's patch-HEV in situ: the multistep model confirmed and refined. Immunity 3, 99-108 (1995).

19. Warnock, R.A., Askari, S., Butcher, E.C. \& von Andrian, U.H. Molecular mechanisms of lymphocyte homing to peripheral lymph nodes. J. Exp. Med. 187, 205-216 (1998).

20. Gallatin, W.M., Weissman, I.L. \& Butcher, E.C. A cell-surface molecule involved in organ-specific homing of lymphocytes. Nature 304, 30-34 (1983).

21. Streeter, P.R., Rouse, B.T.N. \& Butcher, E.C. Immunohistologic and functional characterization of a vascular addressin involved in lymphocyte homing into peripheral lymph nodes. J. Cell Biol. 107, 1853-1862 (1988).

22. Ley, K. \& Kansas, G.S. Selectins in T-cell recruitment to non-lymphoid tissues and sites of inflammation. Nat. Rev. Immunol. 4, 325-335 (2004).

23. Warnock, R.A. et al. The role of chemokines in the microenvironmental control of T versus B cell arrest in Peyer's patch high endothelial venules. J. Exp. Med. 191, 77-88 (2000).

24. Stein, J.V. et al. The CC chemokine thymus-derived chemotactic agent 4 (TCA-4, secondary lymphoid tissue chemokine, 6Ckine, exodus-2) triggers lymphocyte function-associated antigen 1-mediated arrest of rolling T lymphocytes in peripheral lymph node high endothelial venules. J. Exp. Med. 191, 61-76 (2000).

25. Okada, T. et al. Chemokine requirements for $\mathrm{B}$ cell entry to lymph nodes and Peyer's patches. J. Exp. Med. 196, 65-75 (2002).

26. Weninger, W., Crowley, M.A., Manjunath, N. \& von Andrian, U.H. Migratory properties of naïve, effector, and memory CD8(+) T cells. J. Exp. Med. 194, 953-966 (2001).

27. Berlin-Rufenach, C. et al. Lymphocyte migration in lymphocyte functionassociated antigen (LFA)-1- deficient mice. J. Exp. Med. 189, 1467-1478 (1999).

28. Ebisuno, Y. et al. Cutting edge: the B cell chemokine CXC chemokine ligand 13/B lymphocyte chemoattractant is expressed in the high endothelial venules of lymph nodes and Peyer's patches and affects B cell trafficking across high endothelial venules. J. Immunol. 171, 1642-1646 (2003).

29. Nakache, M., Berg, E.L., Streeter, P.R. \& Butcher, E.C. The mucosal vascular addressin is a tissue-specific endothelial cell adhesion molecule for circulating lymphocytes. Nature 337, 179-181 (1989).

30. Berlin, C. et al. a4 b7 integrin mediates lymphocyte binding to the mucosal vascular addressin MAdCAM-1. Cell 74, 185-195 (1993).

31. Berg, E.L., McEvoy, L.M., Berlin, C., Bargatze, R.F. \& Butcher, E.C. L-selectinmediated lymphocyte rolling on MAdCAM-1. Nature 366, 695-698 (1993).

32. Wagner, N. et al. Critical role for b7 integrins in formation of the gutassociated lymphoid tissue. Nature 382, 366-370 (1996).

33. Berlin, C. et al. a4 integrins mediate lymphocyte attachment and rolling under physiologic flow. Cell 80, 413-422 (1995).

34. McHeyzer-Williams, L.J. \& McHeyzer-Williams, M.G. Antigen-specific memory B cell development. Annu. Rev. Immunol. 23, 487-513 (2005).

35. Cyster, J.G. Homing of antibody secreting cells. Immunol. Rev. 194, 48-60 (2003).

36. Kunkel, E.J. \& Butcher, E.C. Plasma-cell homing. Nat. Rev. Immunol. 3, 822-829 (2003).

37. Hargreaves, D.C. et al. A coordinated change in chemokine responsiveness guides plasma cell movements. J. Exp. Med. 194, 45-56 (2001).

38. Underhill, G.H., Minges Wols, H.A., Fornek, J.L., Witte, P.L. \& Kansas, G.S. IgG plasma cells display a unique spectrum of leukocyte adhesion and homing molecules. Blood 99, 2905-2912 (2002).

39. Nitschke, L., Floyd, H., Ferguson, D.J. \& Crocker, P.R. Identification of CD22 ligands on bone marrow sinusoidal endothelium implicated in CD22-dependent homing of recirculating B cells. J. Exp. Med. 189, 1513-1518 (1999).

40. Butcher, E.C. et al. Surface phenotype of Peyer's patch germinal center cells: implications for the role of germinal centers in B cell differentiation. J. Immunol. 129, 2698-2707 (1982).

41. Rudzik, O., Perey, D.Y. \& Bienenstock, J. Differential IgA repopulation after transfer of autologous and allogeneic rabbit Peyer's patch cells. J. Immunol. 114, 40-44 (1975). 
42. McDermott, M.R. \& Bienenstock, J. Evidence for a common mucosal immunologic system. I. Migration of B immunoblasts into intestinal, respiratory, and genital tissues. J. Immunol. 122, 1892-1898 (1979).

43. Tseng, J. Transfer of lymphocytes of Peyer's patches between immunoglobulin allotype congenic mice: repopulation of the IgA plasma cells in the gut lamina propria. J. Immunol. 127, 2039-2043 (1981).

44. Husband, A.J. Kinetics of extravasation and redistribution of IgAspecific antibody-containing cells in the intestine. J. Immunol. 128, 1355-1359 (1982).

45. Husband, A.J. \& Gowans, J.L. The origin and antigen-dependent distribution of IgA-containing cells in the intestine. J. Exp. Med. 148, 1146-1160 (1978)

46. Farstad, I.N. et al. Human intestinal B-cell blasts and plasma cells express the mucosal homing receptor integrin alpha 4 beta 7 . Scand. J. Immunol. 42, 662-672 (1995).

47. Wilson, E. \& Butcher, E.C. CCL28 controls immunoglobulin (Ig)A plasma cell accumulation in the lactating mammary gland and IgA antibody transfer to the neonate. J. Exp. Med. 200, 805-809 (2004).

48. Pan, J. et al. A novel chemokine ligand for CCR10 and CCR3 expressed by epithelial cells in mucosal tissues. J. Immunol. 165, 2943-2949 (2000).

49. Kunkel, E.J. et al. CCR10 expression is a common feature of circulating and mucosal epithelial tissue IgA Ab-secreting cells. J. Clin. Invest. 111, 1001-1010 (2003)

50. Wang, W. et al. Identification of a novel chemokine (CCL28), which binds CCR10 (GPR2). J. Biol. Chem. 275, 22313-22323 (2000).

51. Lazarus, N.H. et al. A common mucosal chemokine (mucosaeassociated epithelial chemokine/CCL28) selectively attracts IgA plasmablasts. J. Immunol. 170, 3799-3805 (2003).

52. Hieshima, K. et al. CC chemokine ligands 25 and 28 play essential roles in intestinal extravasation of IgA antibody-secreting cells. J. Immunol. 173, 3668-3675 (2004).

53. Bowman, E.P. et al. The intestinal chemokine thymus-expressed chemokine (CCL25) attracts IgA antibody-secreting cells. J. Exp. Med. 195, 269-275 (2002)

54. Pabst, O. et al. Chemokine receptor CCR9 contributes to the localization of plasma cells to the small intestine. J. Exp. Med. 199, 411-416 (2004).

55. Feng, N. et al. Redundant role of chemokines CCL25/TECK and CCL28/MEC in IgA+plasmablast recruitment to the intestinal Plamina propria after rotavirus infection. J. Immunol. 176, 5749-5759 (2006).

56. Brown, W.R. \& Kloppel, T.M. The liver and IgA: immunological, cell biological and clinical implications. Hepatology 9, 763-784 (1989).

57. Orlans, E., Peppard, J., Reynolds, J. \& Hall, J. Rapid active transport of immunoglobulin A from blood to bile. J. Exp. Med. 147, 588-592 (1978).

58. Bernasconi, N.L., Traggiai, E. \& Lanzavecchia, A. Maintenance of serological memory by polyclonal activation of human memory B cells. Science 298, 2199-2202 (2002).

59. Mattioli, C.A. \& Tomasi, T.B. Jr The life span of IgA plasma cells from the mouse intestine. J. Exp. Med. 138, 452-460 (1973).

60. Hiepe, F. \& Radbruch, A. Is long-term humoral immunity in the mucosa provided by long-lived plasma cells? A question still open. Eur. J. Immunol. 36, 1068-1069 (2006).

61. Kantele, A. et al. Cutaneous lymphocyte antigen expression on human effector $B$ cells depends on the site and on the nature of antigen encounter. Eur. J. Immunol. 33, 3275-3283 (2003).

62. Koelle, D.M. et al. Expression of cutaneous lymphocyte-associated antigen by CD8(+) T cells specific for a skin-tropic virus. J. Clin. Invest. 110, 537-548 (2002)

63. Gonzalez, J.C. et al. Expression of cutaneous lymphocyte-associated antigen and $\mathrm{E}$-selectin ligand by circulating human memory $\mathrm{CD} 4+\mathrm{T}$ lymphocytes specific for herpes simplex virus type 2. J. Infect. Dis. 191, 243-254 (2005).

64. Koelle, D.M., Gonzalez, J.C. \& Johnson, A.S. Homing in on the cellular immune response to HSV-2 in humans. Am. J. Reprod. Immunol. 53, 172-181 (2005).

65. Liu, L., Fuhlbrigge, R.C., Karibian, K., Tian, T. \& Kupper, T.S. Dynamic programming of $\mathrm{CD} 8+\mathrm{T}$ cell trafficking after live viral immunization. Immunity 25, 511-520 (2006).

66. Rott, L.S. et al. Expression of mucosal homing receptor alpha4beta7 by circulating CD4+cells with memory for intestinal rotavirus. J. Clin. Invest. 100, 1204-1208 (1997).
67. Kantele, A., Zivny, J., Hakkinen, M., Elson, C.O. \& Mestecky, J. Differential homing commitments of antigen-specific T cells after oral or parenteral immunization in humans. J. Immunol. 162, 5173-5177 (1999).

68. Lundin, B.S., Johansson, C. \& Svennerholm, A.M. Oral immunization with a Salmonella enterica serovar typhi vaccine induces specific circulating mucosa-homing CD4(+) and CD8(+) T cells in humans. Infect. Immun. 70, 5622-5627 (2002).

69. Rojas, O.L. et al. Human rotavirus specific T cells: quantification by ELISPOT and expression of homing receptors on CD4+T cells. Virology 314, 671-679 (2003).

70. Quiding-Jarbrink, M. et al. Differential expression of tissue-specific adhesion molecules on human circulating antibody-forming cells after systemic, enteric, and nasal immunizations. A molecular basis for the compartmentalization of effector B cell responses. J. Clin. Invest. 99, 1281-1286 (1997).

71. Kantele, A. et al. Homing potentials of circulating lymphocytes in humans depend on the site of activation: oral, but not parenteral, typhoid vaccination induces circulating antibody-secreting cells that all bear homing receptors directing them to the gut. J. Immunol. 158, 574-579 (1997).

72. Kantele, A., Westerholm, M., Kantele, J.M., Makela, P.H. \& Savilahti, E. Homing potentials of circulating antibody-secreting cells after administration of oral or parenteral protein or polysaccharide vaccine in humans. Vaccine 17, 229-236 (1999).

73. Kantele, A. et al. Unique characteristics of the intestinal immune system as an inductive site after antigen reencounter. J. Infect. Dis. 191, 312-317 (2005).

74. Jung, S. et al. In vivo depletion of $\mathrm{CD} 11 \mathrm{c}(+)$ dendritic cells abrogates priming of CD8(+) T cells by exogenous cell-associated antigens. Immunity 17, 211-220 (2002).

75. Probst, H.C. \& van den Broek, M. Priming of CTLs by lymphocytic choriomeningitis virus depends on dendritic cells. J. Immunol. 174, 3920-3924 (2005).

76. Craxton, A., Magaletti, D., Ryan, E.J. \& Clark, E.A. Macrophage- and dendritic cell-dependent regulation of human B-cell proliferation requires the TNF family ligand BAFF. Blood 101, 4464-4471 (2003).

77. Poeck, H. et al. Plasmacytoid dendritic cells, antigen, and CpG-C license human $B$ cells for plasma cell differentiation and immunoglobulin production in the absence of T-cell help. Blood 103, 3058-3064 (2004).

78. Wykes, M., Pombo, A., Jenkins, C. \& MacPherson, G.G. Dendritic cells interact directly with naive $B$ lymphocytes to transfer antigen and initiate class switching in a primary T-dependent response. J. Immunol. 161, 1313-1319 (1998).

79. Bergtold, A., Desai, D.D., Gavhane, A. \& Clynes, R. Cell surface recycling of internalized antigen permits dendritic cell priming of $B$ cells. Immunity 23, 503-514 (2005).

80. Qi, H., Egen, J.G., Huang, A.Y. \& Germain, R.N. Extrafollicular activation of lymph node B cells by antigen-bearing dendritic cells. Science $\mathbf{3 1 2}$ 1672-1676 (2006)

81. Spalding, D.M., Williamson, S.I., Koopman, W.J. \& McGhee, J.R Preferential induction of polyclonal IgA secretion by murine Peyer's patch dendritic cell-T cell mixtures. J. Exp. Med. 160, 941-946 (1984).

82. Spalding, D.M. \& Griffin, J.A. Different pathways of differentiation of pre-B cell lines are induced by dendritic cells and T cells from different lymphoid tissues. Cell 44, 507-515 (1986).

83. Sato, A. et al. CD11b+Peyer's patch dendritic cells secrete IL-6 and induce IgA secretion from naive B cells. J. Immunol. 171, 3684-3690 (2003).

84. Stagg, A.J., Kamm, M.A. \& Knight, S.C. Intestinal dendritic cells increase T cell expression of alpha4beta7 integrin. Eur. J. Immunol. 32, 1445-1454 (2002)

85. Mora, J.R. et al. Selective imprinting of gut-homing T cells by Peyer's patch dendritic cells. Nature 424, 88-93 (2003).

86. Johansson-Lindbom, B. et al. Selective generation of gut tropic T cells in gut-associated lymphoid tissue (GALT): requirement for GALT dendritic cells and adjuvant. J. Exp. Med. 198, 963-969 (2003).

87. Dudda, J.C., Simon, J.C. \& Martin, S. Dendritic cell immunization route determines CD8+T cell trafficking to inflamed skin: role for tissue microenvironment and dendritic cells in establishment of T cell-homing subsets. J. Immunol. 172, 857-863 (2004). 
88. Mora, J.R. et al. Reciprocal and dynamic control of CD8 T cell homing by dendritic cells from skin- and gut-associated lymphoid tissues. J. Exp. Med. 201, 303-316 (2005).

89. Dudda, J.C. et al. Dendritic cells govern induction and reprogramming of polarized tissue-selective homing receptor patterns of T cells: important roles for soluble factors and tissue microenvironments. Eur. J. Immunol. 35, 1056-1065 (2005).

90. Mora, J.R. et al. Generation of gut-homing lgA-secreting B cells by intestinal dendritic cells. Science 314, 1157-1160 (2006).

91. Phan, T.G., Grigorova, I., Okada, T. \& Cyster, J.G. Subcapsular encounter and complement-dependent transport of immune complexes by lymph node B cells. Nat. Immunol. 8, 992-1000 (2007).

92. Carrasco, Y.R. \& Batista, F.D. B cells acquire particulate antigen in a macrophage-rich area at the boundary between the follicle and the subcapsular sinus of the lymph node. Immunity 27, 160-171 (2007).

93. Junt, T. et al. Subcapsular sinus macrophages in lymph nodes clear lymph-borne viruses and present them to antiviral B cells. Nature 450, 110-114 (2007).

94. Denning, T.L., Wang, Y.C., Patel, S.R., Williams, I.R. \& Pulendran, B. Lamina propria macrophages and dendritic cells differentially induce regulatory and interleukin 17-producing T cell responses. Nat. Immunol. 8, 1086-1094 (2007).

95. McDermott, M.R. et al. Impaired intestinal localization of mesenteric lymphoblasts associated with vitamin A deficiency and protein-calorie malnutrition. Immunology 45, 1-5 (1982).

96. Bjersing, J.L., Telemo, E., Dahlgren, U. \& Hanson, L.A. Loss of ileal IgA+plasma cells and of CD4+lymphocytes in ileal Peyer's patches of vitamin A deficient rats. Clin. Exp. Immunol. 130, 404-408 (2002).

97. Iwata, M. et al. Retinoic acid imprints gut-homing specificity on $\mathrm{T}$ cells. Immunity 21, 527-538 (2004).

98. Lampen, A., Meyer, S., Arnhold, T. \& Nau, H. Metabolism of vitamin $A$ and its active metabolite all-trans-retinoic acid in small intestinal enterocytes. J. Pharmacol. Exp. Ther. 295, 979-985 (2000).

99. Saurer, L., McCullough, K.C. \& Summerfield, A. In vitro induction of mucosa-type dendritic cells by all-trans retinoic acid. J. Immunol. 179, 3504-3514 (2007).

100. Campbell, D.J. \& Butcher, E.C. Rapid acquisition of tissue-specific homing phenotypes by CD4(+) T cells activated in cutaneous or mucosal lymphoid tissues. J. Exp. Med. 195, 135-141 (2002).

101. Svensson, M. et al. CCL25 mediates the localization of recently activated CD8alphabeta(+) lymphocytes to the small-intestinal mucosa. J. Clin. Invest. 110, 1113-1121 (2002).

102. Berberich, S., Forster, R. \& Pabst, O. The peritoneal micromilieu commits B cells to home to body cavities and the small intestine. Blood 109, 4627-4634 (2007).

103. Masopust, D. et al. Activated primary and memory CD8 T cells migrate to nonlymphoid tissues regardless of site of activation or tissue of origin. J. Immunol. 172, 4875-4882 (2004).

104. Dirami, G. et al. Lung retinol storing cells synthesize and secrete retinoic acid, an inducer of alveolus formation. Am. J. Physiol. Lung Cell Mol. Physiol. 286, L249-L256 (2004).

105. Martucci, R.B. et al. Beta-carotene storage, conversion to retinoic acid, and induction of the lipocyte phenotype in hepatic stellate cells. J. Cell Biochem. 92, 414-423 (2004).

106. Mora, J.R. \& von Andrian, U.H. Retinoic acid: an educational "vitamin elixir" for gut-seeking T cells. Immunity 21, 458-460 (2004).

107. Kroese, F.G., Butcher, E.C., Stall, A.M. \& Herzenberg, L.A. A major peritoneal reservoir of precursors for intestinal IgA plasma cells. Immunol. Invest. 18, 47-58 (1989).

108. Kroese, F.G. et al. Many of the IgA producing plasma cells in murine gut are derived from self-replenishing precursors in the peritoneal cavity. Int. Immunol. 1, 75-84 (1989).

109. Macpherson, A.J. et al. A primitive T cell-independent mechanism of intestinal mucosal lgA responses to commensal bacteria. Science $\mathbf{2 8 8}$, 2222-2226 (2000)

110. Thurnheer, M.C., Zuercher, A.W., Cebra, J.J. \& Bos, N.A. B1 cells contribute to serum IgM, but not to intestinal IgA, production in gnotobiotic Ig allotype chimeric mice. J. Immunol. 170, 4564-4571 (2003).

111. Boursier, L., Farstad, I.N., Mellembakken, J.R., Brandtzaeg, P. \& Spencer, J. IgVH gene analysis suggests that peritoneal B cells do not contribute to the gut immune system in man. Eur. J. Immunol. 32, 2427-2436 (2002)

112. McGhee, J.R., Kunisawa, J. \& Kiyono, H. Gut lymphocyte migration: we are halfway 'home'. Trends Immunol. 28, 150-153 (2007).

113. Ansel, K.M., Harris, R.B. \& Cyster, J.G. CXCL13 is required for B1 cell homing, natural antibody production, and body cavity immunity. Immunity 16, 67-76 (2002).

114. Ha, S.A. et al. Regulation of B1 cell migration by signals through Toll-like receptors. J. Exp. Med. 203, 2541-2550 (2006).

115. He, B. et al. Intestinal bacteria trigger T cell-independent immunoglobulin A(2) class switching by inducing epithelial-cell secretion of the cytokine APRIL. Immunity 26, 812-826 (2007).

116. Muramatsu, M. et al. Class switch recombination and hypermutation require activation-induced cytidine deaminase (AID), a potential RNA editing enzyme. Cell 102, 553-563 (2000).

117. Kinoshita, K., Harigai, M., Fagarasan, S., Muramatsu, M. \& Honjo, T. A hallmark of active class switch recombination: transcripts directed by I promoters on looped-out circular DNAs. Proc. Natl. Acad. Sci. USA 98, 12620-12623 (2001).

118. Bergqvist, P., Gardby, E., Stensson, A., Bemark, M. \& Lycke, N.Y. Gut IgA class switch recombination in the absence of CD40 does not occur in the lamina propria and is independent of germinal centers. $\mathrm{J}$. Immunol. 177, 7772-7783 (2006).

119. Zuercher, A.W. \& Cebra, J.J. Structural and functional differences between putative mucosal inductive sites of the rat. Eur. J. Immunol. 32 3191-3196 (2002)

120. Crouch, E.E. et al. Regulation of AID expression in the immune response. J. Exp. Med. 204, 1145-1156 (2007).

121. Fagarasan, S., Kinoshita, K., Muramatsu, M., Ikuta, K. \& Honjo, T. In situ class switching and differentiation to IgA-producing cells in the gut lamina propria. Nature 413, 639-643 (2001)

122. Boursier, L., Gordon, J.N., Thiagamoorthy, S., Edgeworth, J.D. \& Spencer, J. Human intestinal IgA response is generated in the organized gut-associated lymphoid tissue but not in the lamina propria. Gastroenterology 128, 1879-1889 (2005).

123. Shikina, T. et al. IgA class switch occurs in the organized nasopharynxand gut-associated lymphoid tissue, but not in the diffuse lamina propria of airways and gut. J. Immunol. 172, 6259-6264 (2004).

124. Yamamoto, M. et al. Role of gut-associated lymphoreticular tissues in antigen-specific intestinal lgA immunity. J. Immunol. 173, 762-769 (2004).

125. Hashizume, T. et al. Isolated lymphoid follicles are not IgA inductive sites for recombinant Salmonella. Biochem. Biophys. Res. Commun. 360, 388-393 (2007).

126. van Ginkel, F.W. et al. Partial lgA-deficiency with increased Th2-type cytokines in TGF-beta 1 knockout mice. J. Immunol. 163, 1951-1957 (1999).

127. Cazac, B.B. \& Roes, J. TGF-beta receptor controls B cell responsiveness and induction of IgA in vivo. Immunity 13, 443-451 (2000).

128. Borsutzky, S., Cazac, B.B., Roes, J. \& Guzman, C.A. TGF-beta receptor signaling is critical for mucosal IgA responses. J. Immunol. 173, 3305-3309 (2004)

129. Klein, J. et al. B cell-specific deficiency for Smad2 in vivo leads to defects in TGF-beta-directed lgA switching and changes in B cell fate. J. Immunol. 176, 2389-2396 (2006).

130. Nikawa, T. et al. Impaired vitamin A-mediated mucosal IgA response in IL-5 receptor-knockout mice. Biochem. Biophys. Res. Commun. 285, 546-549 (2001).

131. Harriman, G.R., Kunimoto, D.Y., Elliott, J.F., Paetkau, V. \& Strober, W. The role of IL-5 in IgA B cell differentiation. J. Immunol. 140, 3033-3039 (1988).

132. Schoenbeck, S., McKenzie, D.T. \& Kagnoff, M.F. Interleukin 5 is a differentiation factor for IgA B cells. Eur. J. Immunol. 19, 965-969 (1989).

133. Matsumoto, R. et al. Interleukin-5 induces maturation but not class switching of surface IgA-positive B cells into IgA-secreting cells. Immunology 66, 32-38 (1989).

134. Ramsay, A.J. et al. The role of interleukin- 6 in mucosal lgA antibody responses in vivo. Science 264, 561-563 (1994).

135. McGhee, J.R., Fujihashi, K., Beagley, K.W. \& Kiyono, H. Role of interleukin-6 in human and mouse mucosal lgA plasma cell responses. Immunol. Res. 10, 418-422 (1991). 
136. Deviere, J. et al. High interleukin-6 serum levels and increased production by leucocytes in alcoholic liver cirrhosis. Correlation with IgA serum levels and lymphokines production. Clin. Exp. Immunol. 77 , 221-225 (1989).

137. Bromander, A.K., Ekman, L., Kopf, M., Nedrud, J.G. \& Lycke, N.Y. IL-6-deficient mice exhibit normal mucosal IgA responses to local immunizations and Helicobacter felis infection. J. Immunol. 156, 4290-4297 (1996).

138. McGhee, J.R. et al. Role of IL-6 in human antigen-specific and polyclonal IgA responses. Adv. Exp. Med. Biol. 310, 113-121 (1991).

139. Brandt, S.J., Bodine, D.M., Dunbar, C.E. \& Nienhuis, A.W. Dysregulated interleukin 6 expression produces a syndrome resembling Castleman's disease in mice. J. Clin. Invest. 86, 592-599 (1990).

140. Bao, S. et al. Intestinal IgA plasma cells of the B1 lineage are IL-5 dependent. Immunology 94, 181-188 (1998).

141. Yoshida, T. et al. Defective B-1 cell development and impaired immunity against Angiostrongylus cantonensis in IL-5R alpha-deficient mice. Immunity 4, 483-494 (1996).

142. Kopf, M. et al. Impaired immune and acute-phase responses in interleukin-6-deficient mice. Nature 368, 339-342 (1994).

143. Beagley, K.W., Bao, S., Ramsay, A.J., Eldridge, J.H. \& Husband, A.J. IgA production by peritoneal cavity B cells is IL-6 independent: implications for intestinal IgA responses. Eur. J. Immunol. 25 2123-2126 (1995)

144. Barnard, J.A., Beauchamp, R.D., Coffey, R.J. \& Moses, H.L. Regulation of intestinal epithelial cell growth by transforming growth factor type beta. Proc. Natl. Acad. Sci. USA 86, 1578-1582 (1989).

145. Barnard, J.A., Warwick, G.J. \& Gold, L.I. Localization of transforming growth factor beta isoforms in the normal murine small intestine and colon. Gastroenterology 105, 67-73 (1993).

146. Babyatsky, M.W., Rossiter, G. \& Podolsky, D.K. Expression of transforming growth factors alpha and beta in colonic mucosa in inflammatory bowel disease. Gastroenterology 110, 975-984 (1996).

147. Lawrance, I.C., Maxwell, L. \& Doe, W. Inflammation location, but not type, determines the increase in TGF-beta1 and IGF-1 expression and collagen deposition in IBD intestine. Inflamm. Bowel Dis. 7, 16-26 (2001).

148. Iwasaki, A. \& Kelsall, B.L. Freshly isolated Peyer's patch, but not spleen, dendritic cells produce interleukin 10 and induce the differentiation of Thelper type 2 cells. J. Exp. Med. 190, 229-239 (1999).

149. Coombes, J.L. et al. A functionally specialized population of mucosal CD103+DCs induces Foxp3+regulatory T cells via a TGF-\{beta\}- and retinoic acid-dependent mechanism. J. Exp. Med. 204, 1757-1764 (2007).

150. Mucida, D. et al. Reciprocal TH17 and regulatory T cell differentiation mediated by retinoic acid. Science 317, 256-260 (2007).

151. Sun, C.M. et al. Small intestine lamina propria dendritic cells promote de novo generation of Foxp3T reg cells via retinoic acid. J. Exp. Med. 204, 1775-1785 (2007).

152. Travis, M.A. et al. Loss of integrin alpha(v)beta(8) on dendritic cells causes autoimmunity and colitis in mice. Nature 449, 361-365 (2007).

153. Chen, S.S. \& Li, Q. Transforming growth factor-beta 1 (TGF-beta 1) is a bifunctional immune regulator for mucosal IgA responses. Cell Immunol. 128, 353-361 (1990).

154. Sonoda, E. et al. Transforming growth factor beta induces IgA production and acts additively with interleukin 5 for IgA production. J. Exp. Med. 170, 1415-1420 (1989).

155. Coffman, R.L., Lebman, D.A. \& Shrader, B. Transforming growth factor b specifically enhances IgA production by lipopolysaccharide-stimulated murine B lymphocytes. J. Exp. Med. 170, 1039-1044 (1989).

156. Kim, P.H. \& Kagnoff, M.F. Transforming growth factor-beta 1 is a costimulator for IgA production. J. Immunol. 144, 3411-3416 (1990).

157. van Vlasselaer, P., Punnonen, J. \& de Vries, J.E. Transforming growth factor-beta directs IgA switching in human B cells. J. Immunol. 148, 2062-2067 (1992)

158. Lebman, D.A., Lee, F.D. \& Coffman, R.L. Mechanism for transforming growth factor beta and IL-2 enhancement of IgA expression in lipopolysaccharide-stimulated B cell cultures. J. Immunol. 144, 952-959 (1990).

159. Kim, P.H. \& Kagnoff, M.F. Transforming growth factor beta 1 increases IgA isotype switching at the clonal level. J. Immunol. 145, 3773-3778 (1990).
160. Ehrhardt, R.O., Strober, W. \& Harriman, G.R. Effect of transforming growth factor (TGF)-beta 1 on IgA isotype expression. TGF-beta 1 induces a small increase in slgA+B cells regardless of the method of B cell activation. J. Immunol. 148, 3830-3836 (1992).

161. Tezuka, H. et al. Regulation of IgA production by naturally occurring TNF/iNOS-producing dendritic cells. Nature 448, 929-933 (2007).

162. Kaminski, D.A. \& Stavnezer, J. Enhanced lgA class switching in marginal zone and B1 B cells relative to follicular/B2 B cells. J. Immunol. 177, 6025-6029 (2006)

163. Macpherson, A.J. et al. IgA production without mu or delta chain expression in developing B cells. Nat. Immunol. 2, 625-631 (2001)

164. Castigli, E. et al. Impaired IgA class switching in APRIL-deficient mice. Proc. Natl. Acad. Sci. USA 101, 3903-3908 (2004).

165. Castigli, E. et al. TACl and BAFF-R mediate isotype switching in B cells. J. Exp. Med. 201, 35-39 (2005).

166. Schiemann, B. et al. An essential role for BAFF in the normal development of B cells through a BCMA-independent pathway. Science 293, 2111-2114 (2001).

167. Litinskiy, M.B. et al. DCs induce CD40-independent immunoglobulin class switching through BLyS and APRIL. Nat. Immunol. 3, 822-829 (2002).

168. von Bulow, G.U., van Deursen, J.M. \& Bram, R.J. Regulation of the T-independent humoral response by TACl. Immunity 14, 573-582 (2001).

169. Sakurai, D. et al. TACl regulates IgA production by APRIL in collaboration with HSPG. Blood 109, 2961-2967 (2007).

170. Castigli, E. et al. TACl is mutant in common variable immunodeficiency and IgA deficiency. Nat. Genet. 37, 829-834 (2005).

171. Kimata, H. \& Fujimoto, M. Vasoactive intestinal peptide specifically induces human IgA1 and IgA2 production. Eur. J. Immunol. 24, 2262-2265 (1994)

172. Kimata, H. \& Fujimoto, M. Induction of IgA1 and IgA2 production in immature human fetal $B$ cells and pre-B cells by vasoactive intestina peptide. Blood 85, 2098-2104 (1995).

173. Fujieda, S., Waschek, J.A., Zhang, K. \& Saxon, A. Vasoactive intestinal peptide induces S(alpha)/S(mu) switch circular DNA in human B cells. J. Clin. Invest. 98, 1527-1532 (1996).

174. Gonzalez, C., Barroso, C., Martin, C., Gulbenkian, S. \& Estrada, C. Neuronal nitric oxide synthase activation by vasoactive intestinal peptide in bovine cerebral arteries. J. Cereb. Blood Flow Metab. 17, 977-984 (1997).

175. Grider, J.R., Murthy, K.S., Jin, J.G. \& Makhlouf, G.M. Stimulation of nitric oxide from muscle cells by VIP: prejunctional enhancement of VIP release. Am. J. Physiol. 262, G774-G778 (1992).

176. Tokuyama, H. \& Tokuyama, Y. Retinoids enhance IgA production by lipopolysaccharide-stimulated murine spleen cells. Cell. Immunol. 150, 353-363 (1993).

177. Glick, A.B. et al. Complex regulation of TGF beta expression by retinoic acid in the vitamin A-deficient rat. Development 111, 1081-1086 (1991).

178. Glick, A.B., Flanders, K.C., Danielpour, D., Yuspa, S.H. \& Sporn, M.B. Retinoic acid induces transforming growth factor-beta 2 in cultured keratinocytes and mouse epidermis. Cell. Regul. 1, 87-97 (1989).

179. Beagley, K.W. et al. Interleukins and IgA synthesis. Human and murine interleukin 6 induce high rate IgA secretion in IgA-committed B cells. J. Exp. Med. 169, 2133-2148 (1989).

180. Tokuyama, H. \& Tokuyama, Y. Endogenous cytokine expression profiles in retinoic acid-induced lgA production by LPS-stimulated murine splenocytes. Cell. Immunol. 166, 247-253 (1995).

181. Tokuyama, H. \& Tokuyama, $Y$. The regulatory effects of all-trans-retinoic acid on isotype switching: retinoic acid induces IgA switch rearrangement in cooperation with IL-5 and inhibits IgG1 switching. Cell. Immunol. 192, 41-47 (1999).

182. Kuwabara, K., Shudo, K. \& Hori, Y. Novel synthetic retinoic acid inhibits rat collagen arthritis and differentially affects serum immunoglobulin subclass levels. FEBS Lett. 378, 153-156 (1996).

183. Seguin-Devaux, C. et al. Enhancement of the inducible NO synthase activation by retinoic acid is mimicked by RARalpha agonist in vivo. Am. J. Physiol. Endocrinol. Metab. 283, E525-E535 (2002).

184. Devaux, Y. et al. Retinoic acid and host-pathogen interactions: effects on inducible nitric oxide synthase in vivo. Am. J. Physiol. Endocrinol. Metab. 279, E1045-E1053 (2000). 
185. Zou, F. et al. Retinoic acid activates human inducible nitric oxide synthase gene through binding of RARalpha/RXRalpha heterodimer to a novel retinoic acid response element in the promoter. Biochem. Biophys. Res. Commun. 355, 494-500 (2007).

186. Sirisinha, S., Darip, M.D., Moongkarndi, P., Ongsakul, M. \& Lamb, A.J Impaired local immune response in vitamin A-deficient rats. Clin. Exp. Immunol. 40, 127-135 (1980).

187. Kozakova, H. et al. Vitamin A deficiency leads to severe functional disturbance of the intestinal epithelium enzymes associated with diarrhoea and increased bacterial translocation in gnotobiotic rats. Microbes Infect. 5, 405-411 (2003).

188. Wiedermann, U. et al. Vitamin A deficiency increases inflammatory responses. Scand. J. Immunol. 44, 578-584 (1996).

189. Wiedermann, U., Hanson, L.A., Holmgren, J. \& Dahlgren, U.I. Impaired mucosal immune response in vitamin A deficient rats immunized with oral cholera vaccine. Adv. Exp. Med. Biol. 371B, 1629-1631 (1995).

190. Wiedermann, U., Hanson, L.A., Kahu, H. \& Dahlgren, U.I. Aberrant T-cell function in vitro and impaired T-cell dependent antibody response in vivo in vitamin A-deficient rats. Immunology 80, 581-586 (1993).

191. Stephensen, C.B., Moldoveanu, Z. \& Gangopadhyay, N.N. Vitamin A deficiency diminishes the salivary immunoglobulin A response and enhances the serum immunoglobulin $G$ response to influenza $A$ virus infection in BALB/c mice. J. Nutr. 126, 94-102 (1996).
192. Gangopadhyay, N.N., Moldoveanu, Z. \& Stephensen, C.B. Vitamin A deficiency has different effects on immunoglobulin $A$ production and transport during influenza A infection in BALB/c mice. J. Nutr. 126, 2960-2967 (1996)

193. Wiedermann, U., Hanson, L.A., Holmgren, J., Kahu, H. \& Dahlgren, U.I. Impaired mucosal antibody response to cholera toxin in vitamin A-deficient rats immunized with oral cholera vaccine. Infect. Immun. 61, 3952-3957 (1993)

194. Wiedermann, U., Hanson, L.A., Bremell, T., Kahu, H. \& Dahlgren, U.I. Increased translocation of Escherichia coli and development of arthritis in vitamin A-deficient rats. Infect. Immun. 63, 3062-3068 (1995).

195. Sommer, A., Tarwotjo, I., Hussaini, G. \& Susanto, D. Increased mortality in children with mild vitamin A deficiency. Lancet 2, 585-588 (1983).

196. Sommer, A. et al. Impact of vitamin A supplementation on childhood mortality. A randomised controlled community trial. Lancet 1, 1169-1173 (1986).

197. West, K.P Jr et al. Efficacy of vitamin A in reducing preschool child mortality in Nepal. Lancet 338, 67-71 (1991).

198. Lie, C., Ying, C., Wang, E.L., Brun, T. \& Geissler, C. Impact of large-dose vitamin A supplementation on childhood diarrhoea, respiratory disease and growth. Eur. J. Clin. Nutr. 47, 88-96 (1993).

199. Semba, R.D. et al. Effect of periodic vitamin A supplementation on mortality and morbidity of human immunodeficiency virus-infected children in Uganda: A controlled clinical trial. Nutrition 21, 25-31 (2005). 